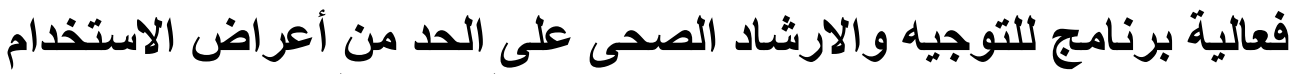

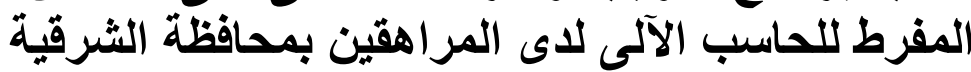

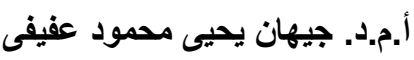

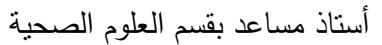

كلية التربية الرياضية بنات

جامعة الزقازيق

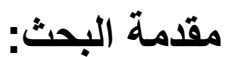

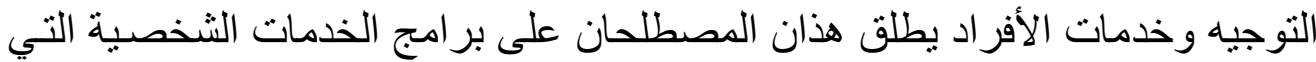

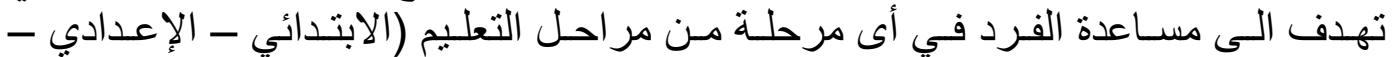

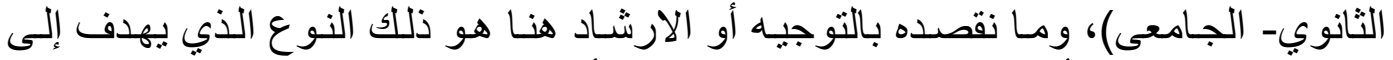

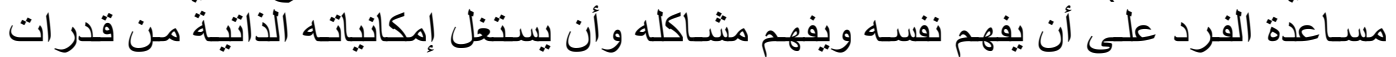
ومهار ات و استعدادات وميول بغرض تحسين صحته و المحافظة عليها وممارسـة السلوك كانك

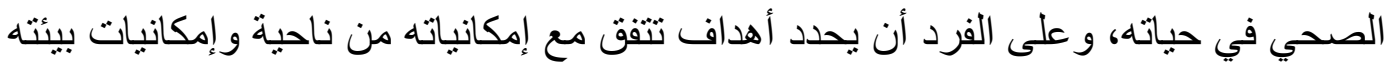

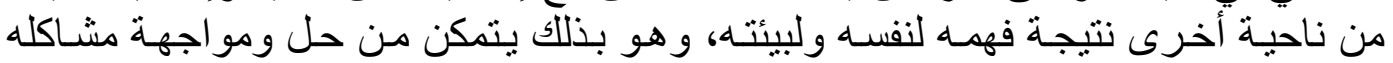

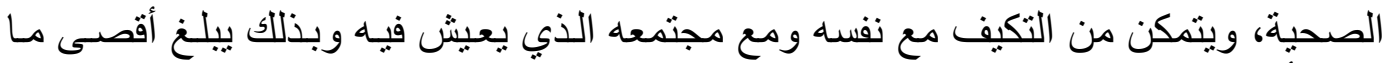
يمكن أن يبلغه من النمو و التكامل في شخصن التهيته.

ويشير "بهاء الدين إبر اهيم سلامة" ( 1 ـ . ب م) إلى أن أغر اض التوجيه في التربية الصحية تتمثل في:

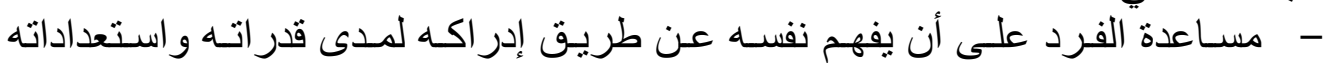

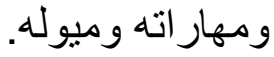

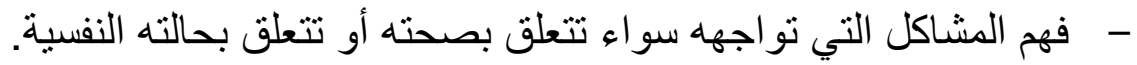

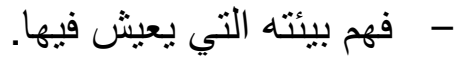

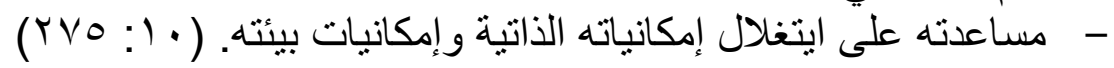

وتتحقق هذه الأغر اض عن طريق الخدمات الصـحية التى تدخل ضـمن برنـامج

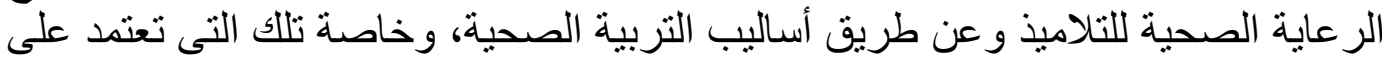

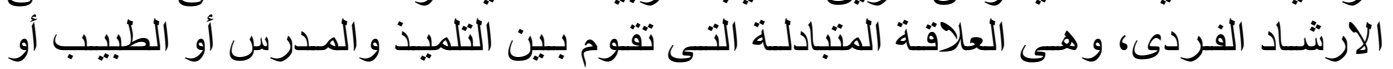

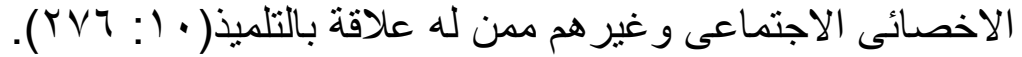

وترتبط أهداف التوجيه و الإرشـاد الصحى ارثباطـاً وثيقاً بالمشـاركة الإيجابيـة بين

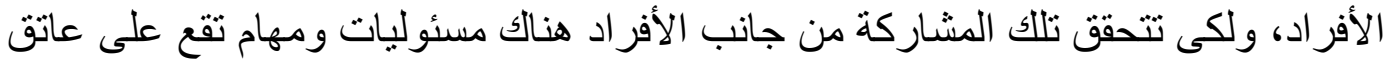

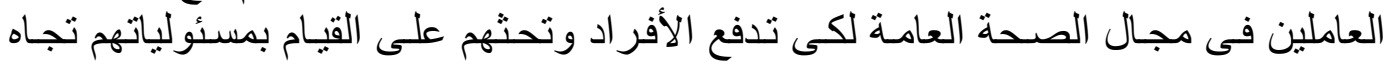
صحتهم، ويتم ذللك عن طريق التربية الصحية.

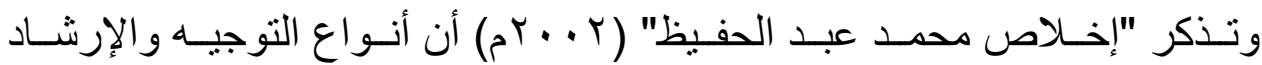

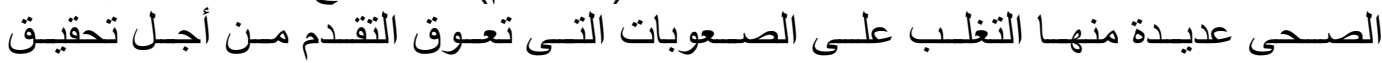

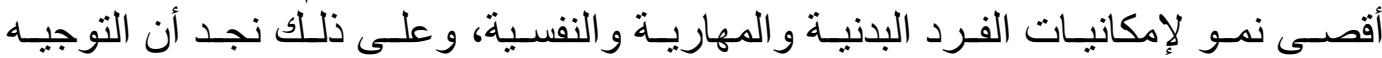




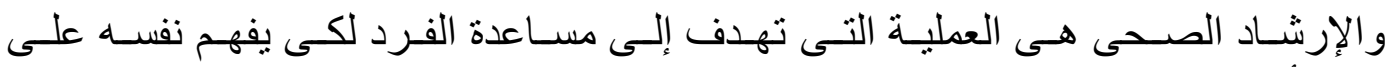

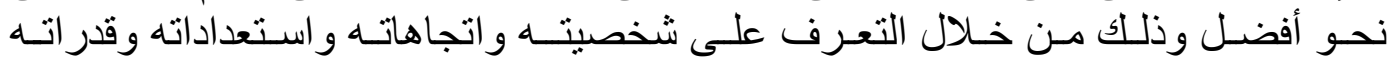

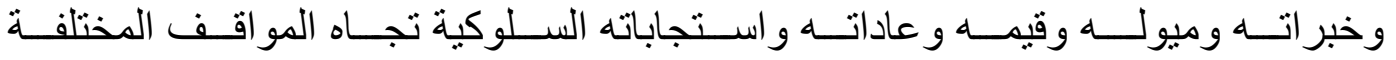

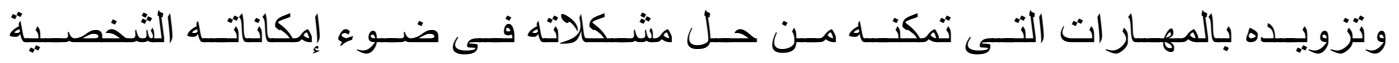

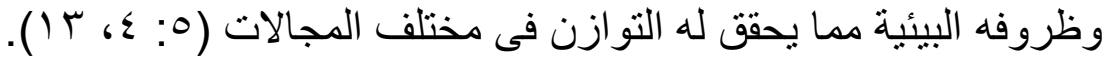

وتشير "الفت حفنى" (r99 (9) إلى أن الإرشاد السلوكى يقوم على نظريـة الإطفاء

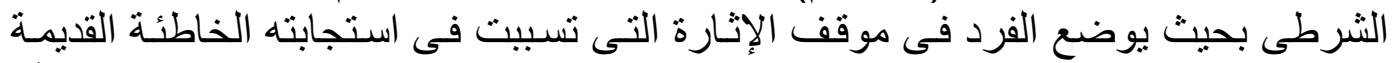

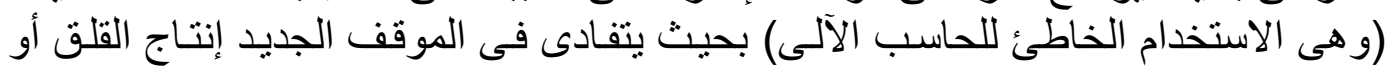

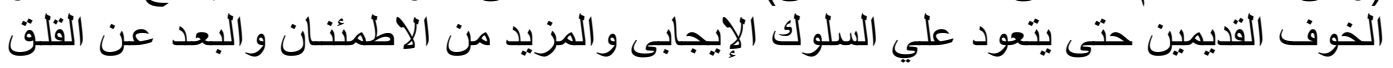

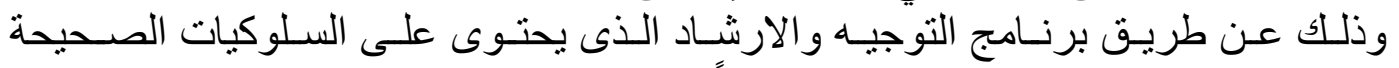

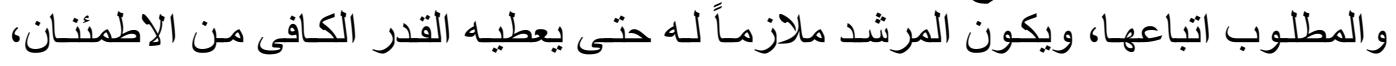

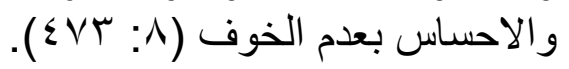

ويعد استخدام الحاسب الآلى فى معظم مجـالات الحيـاة أمر لا جدال فيـه: فيستخدم

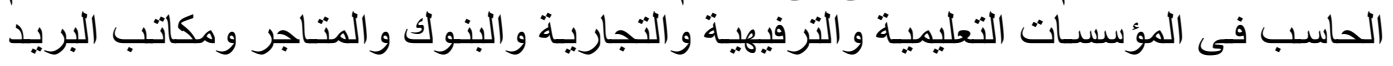

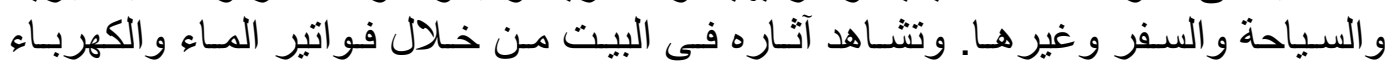

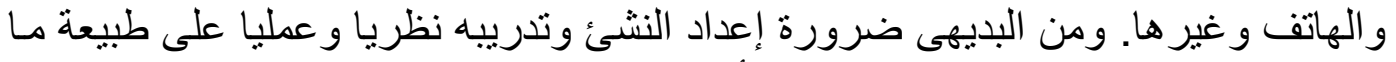

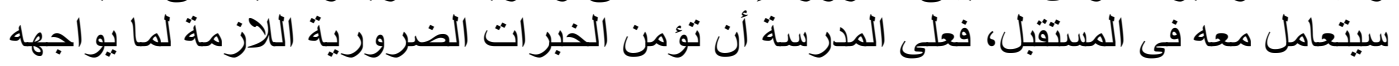

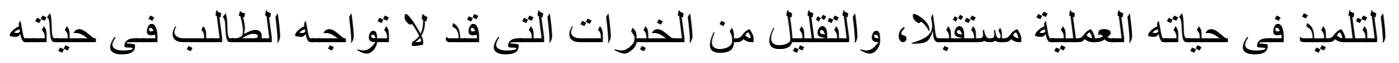

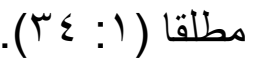

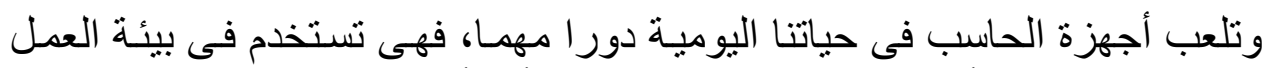

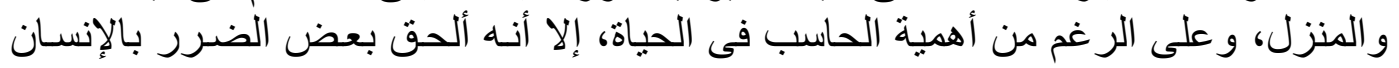
نتيجة لسو استخدامه له وله

فقد أوضح لنا موقع السلامة العربية على شبكة المعلومـات أن الجلوس أمسام جهاز

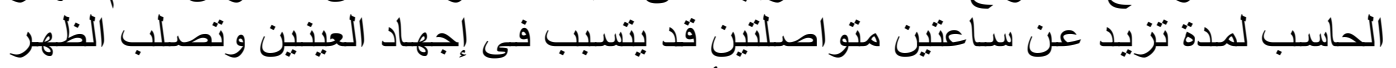

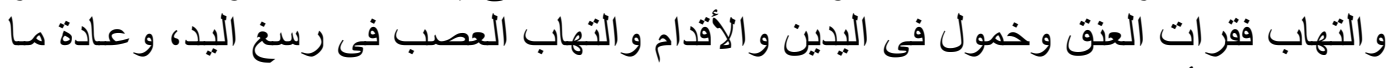

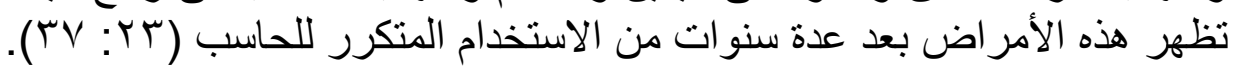

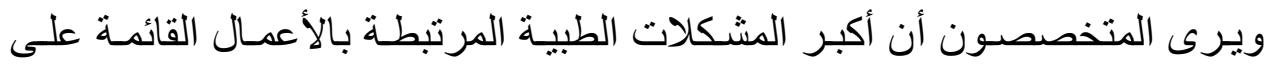

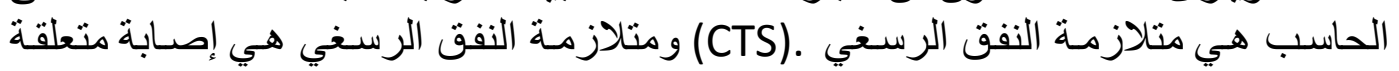

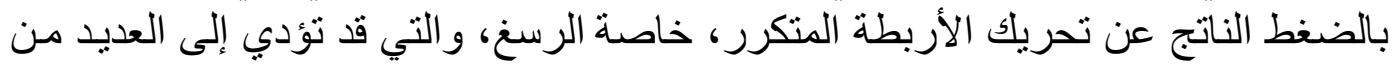

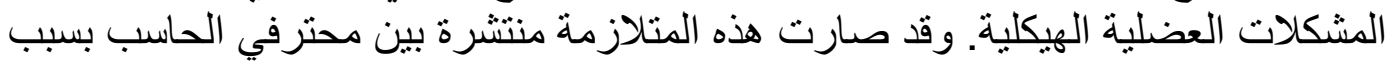

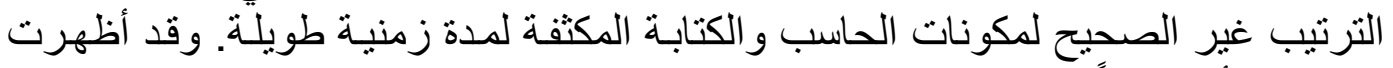

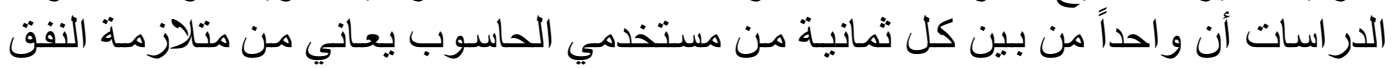

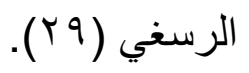




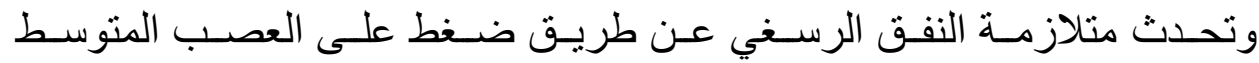

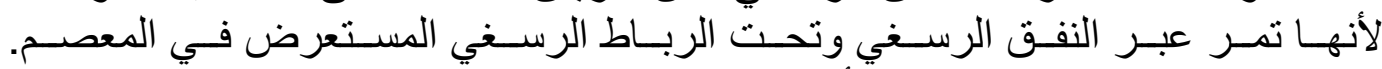

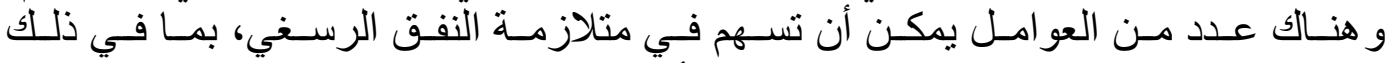
الثكل التشريحى للمعصم، المشاكل الصحية و أنماط استخدام اليد (بانّ).

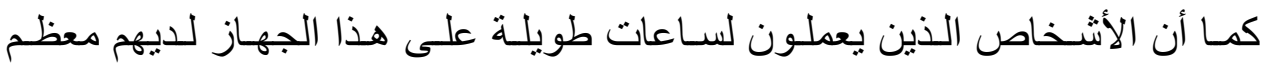

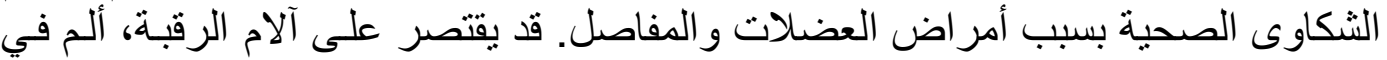

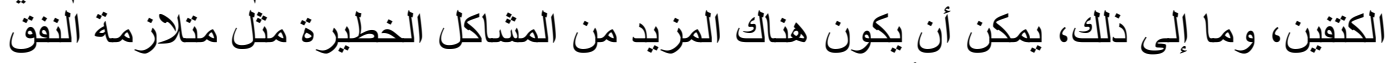

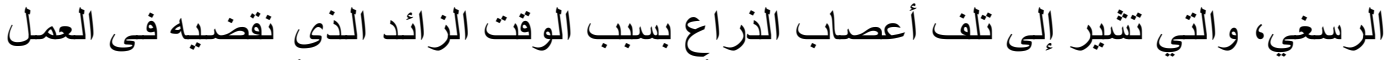

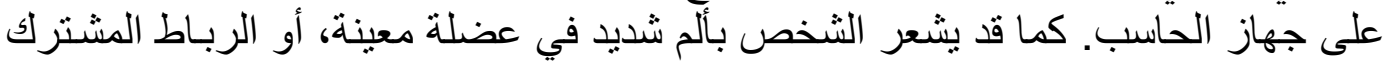

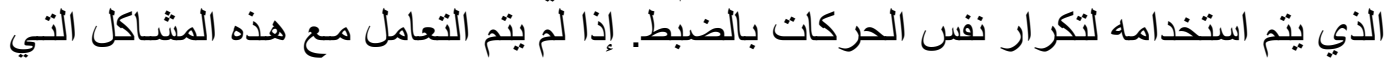
يمكن أن تؤدي إلى ضرر دائم على صحتلك و بالتالي في حياتلك.

ووفقا لأحدث الأبحاث فإن الحاسب يمكن أن يلحق ضررا بالغا بصحة الفرد عندما

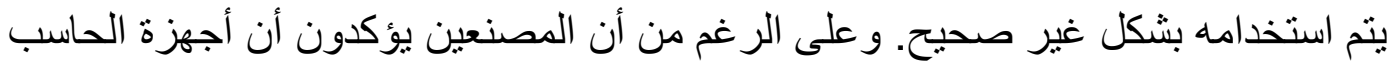

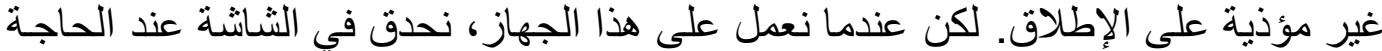

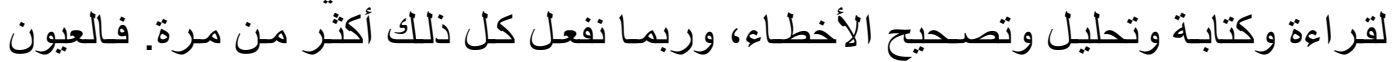

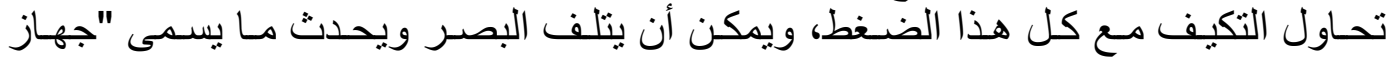

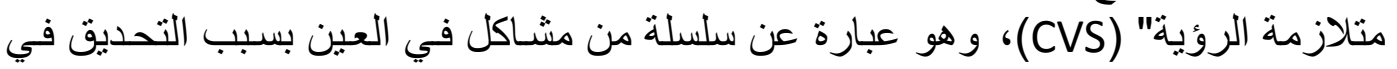
شاثشة جهاز الحاسب لفترة طويلة من الزمن.

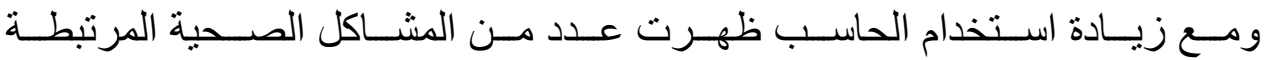

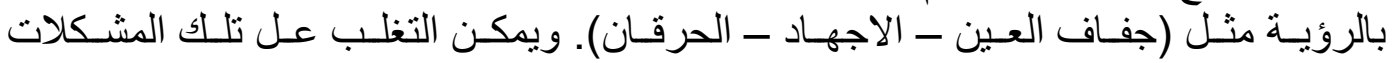

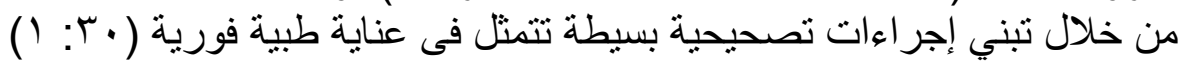

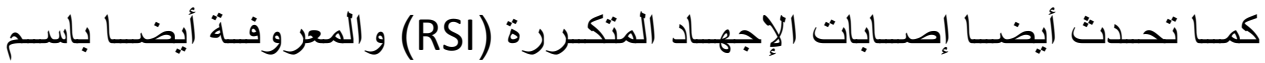

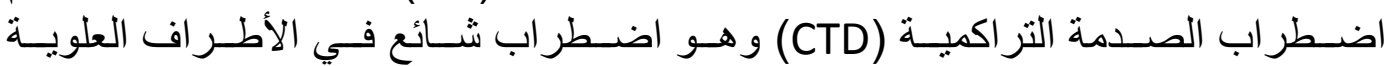

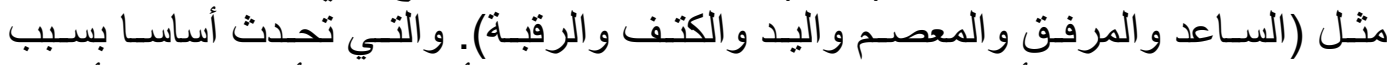

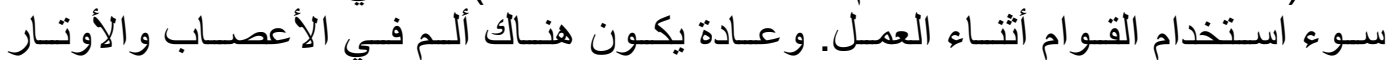

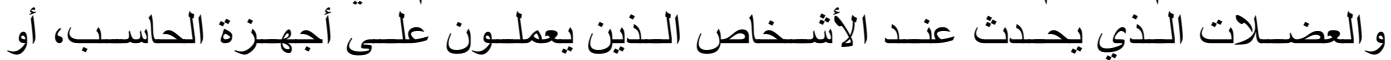

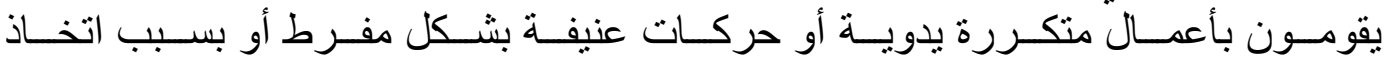
وضعية سيئة للجسم في أثناء القيام بالعمل (rV).

ومن الأعر اض التي يعاني منها المصاب بهذه الحالة نذكر آلالم المفاصل أو تثـنج وضعف العضلات أو تيبس الكفاصل أو الوخز أو الخدر.

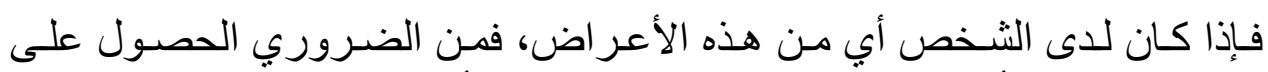

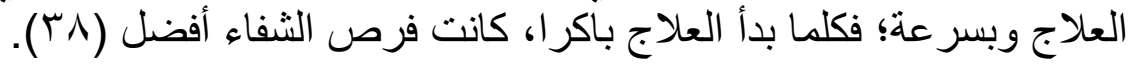




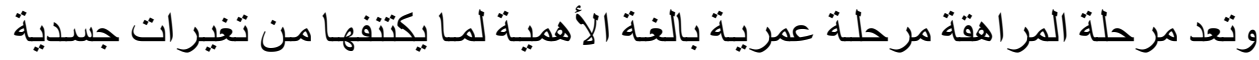

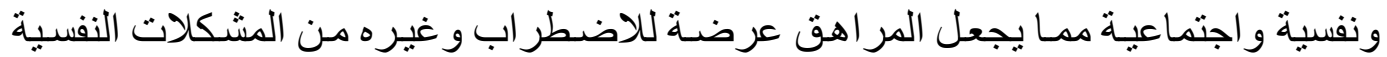

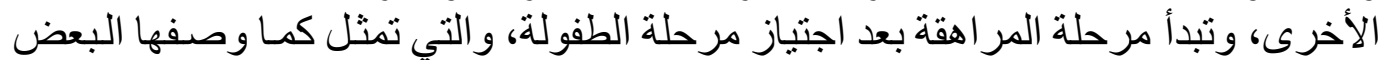

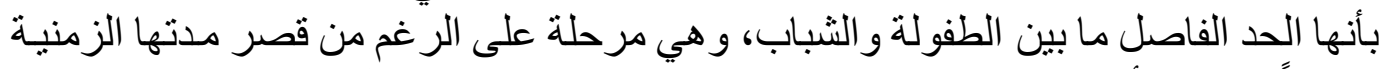

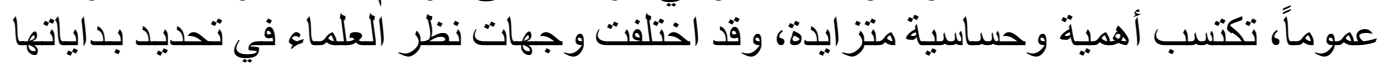
ونهاياتها.

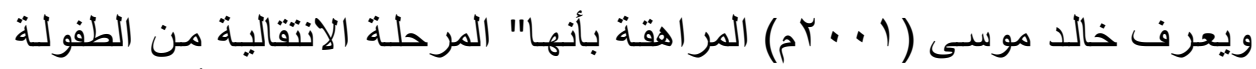

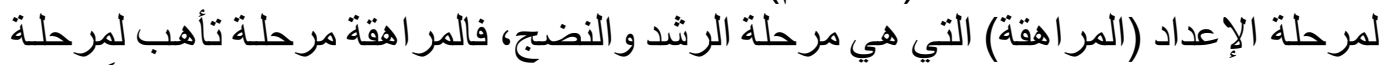

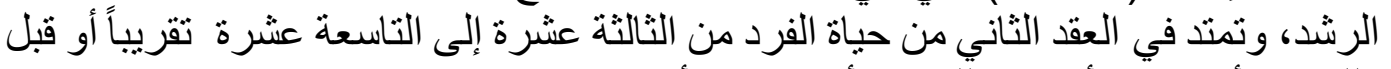

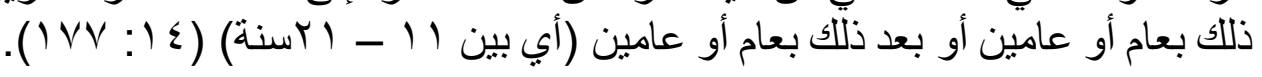

ويقول حامد زهران ( . . . . م) لقد أثبتت البحوث أن للمر اهق أشكالاً وصوراً

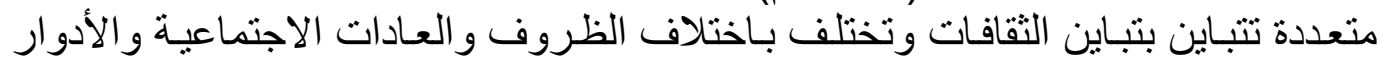

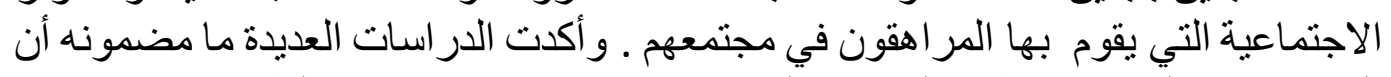

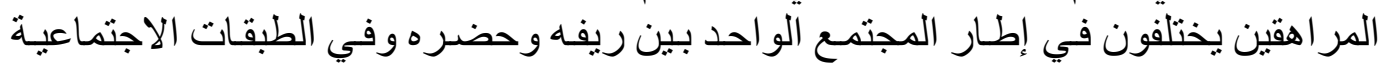

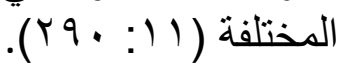

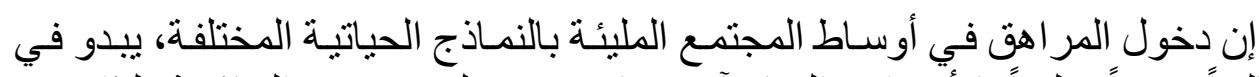

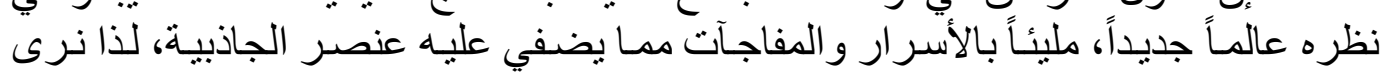

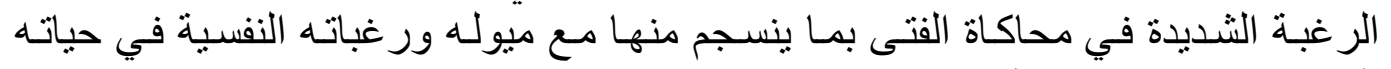
الشخصية والاجتماعية الجديدة.

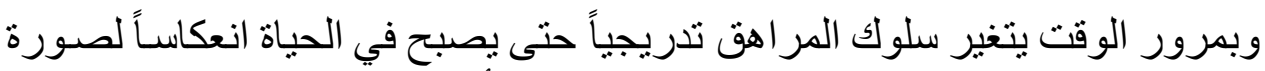

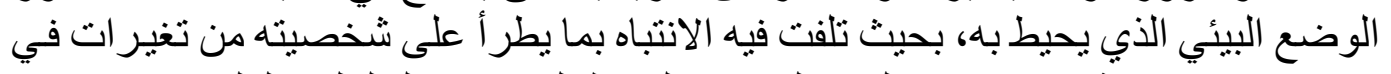
علاقاته الاجتماعية، ومحاو لاته الجادة لمحاكاة الوسط الجديد في السلوك و الملبس التبس. وفي العصر الحالي عصر ثورة تكنولوجيا المعلومات أصبح في متناول الفتى العادي

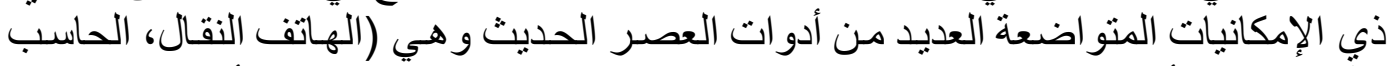

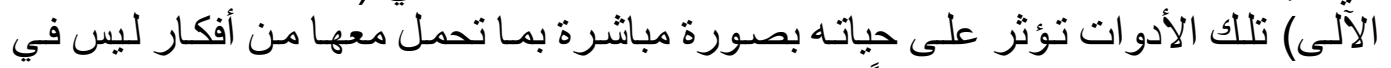

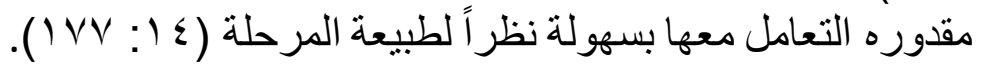

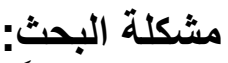

نظر اً لأهمية الصحة للفرد وللمجتمع فقد منحتها مختلف الدول الكثير من عنايتها

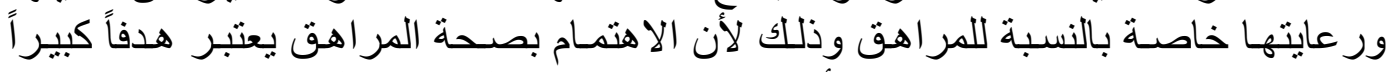

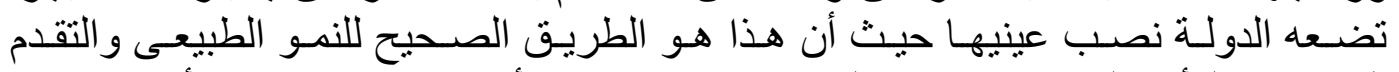

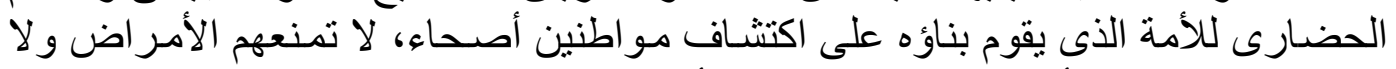

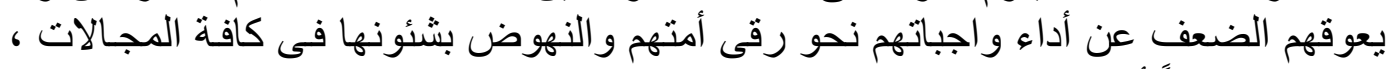

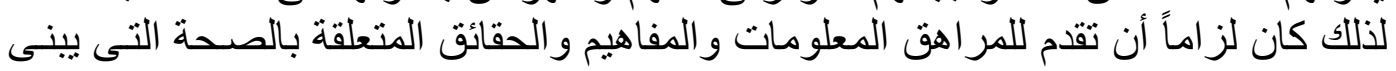

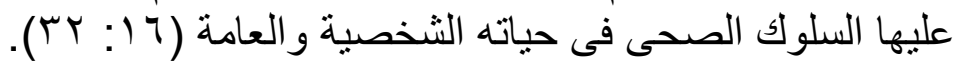


وقد لاحظت الباحثة وجود زيادة مضطردة فى استخدام الحاسب الآلى بكافة أثكاله الأله

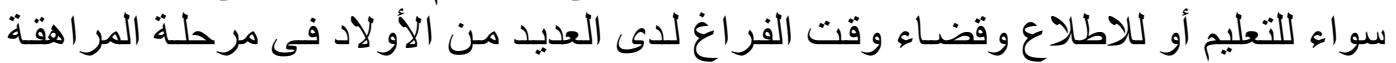

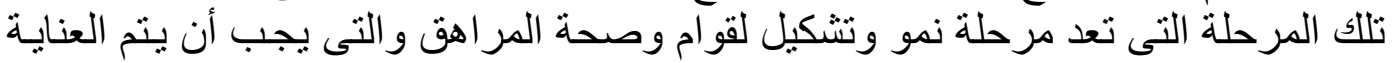

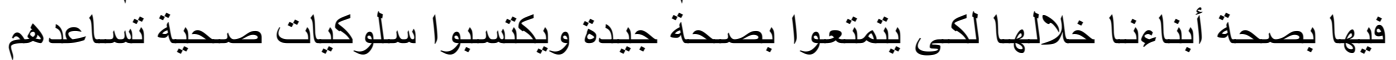

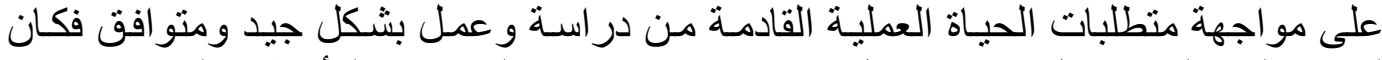

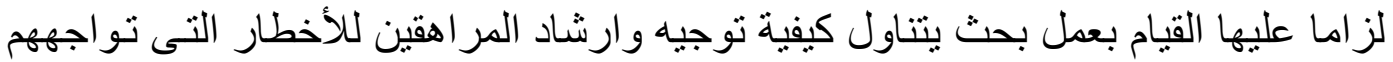
أثناء استخدامهم المفرط للحاسب الآلى ومسـاعدتهم على كيفيـة التغلب على تلى تلك الأخطار للعيش بطريقة صحية سليمة و اكتمال نمو هم بشكل صحسى صحي.

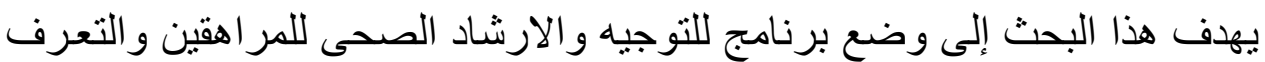
هدف البحث:

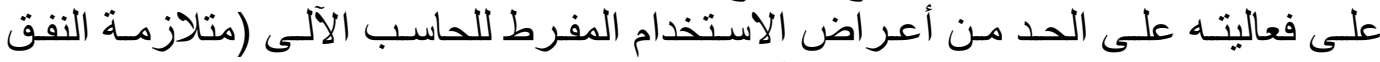

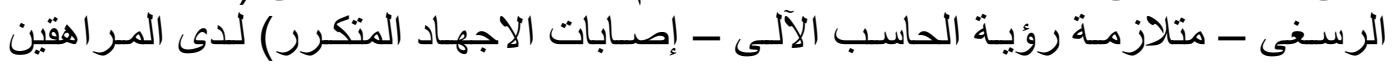
بمحافظة الثرقية.

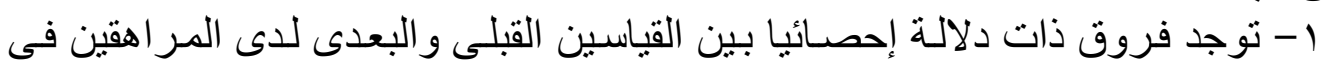

\section{فرض البحث:}

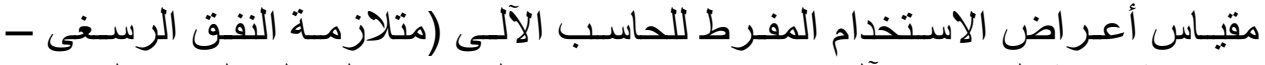

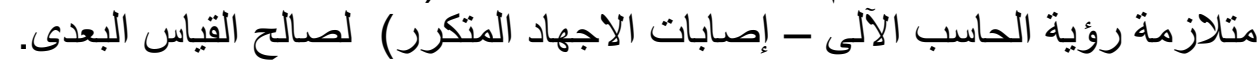

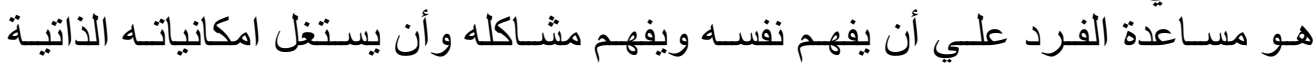

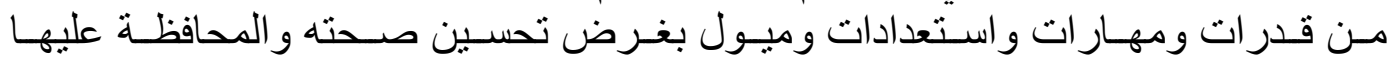

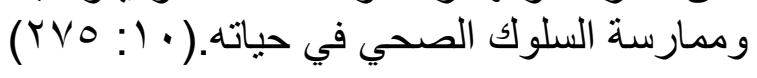

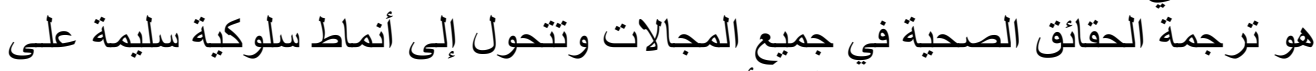

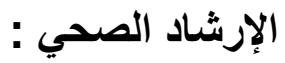

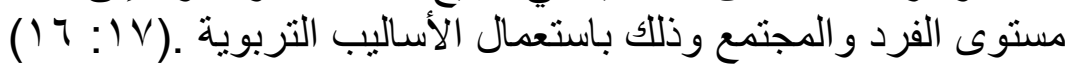

الاستخدام المفرط للحاسب الآلى:

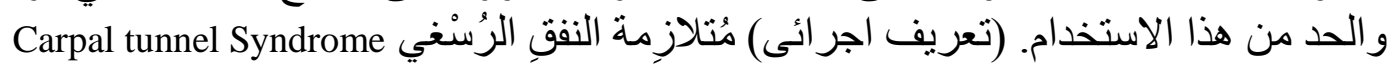

هى من إحدى المشكلات العصبية التي تصبي العصب المسؤول عن الاحساس في

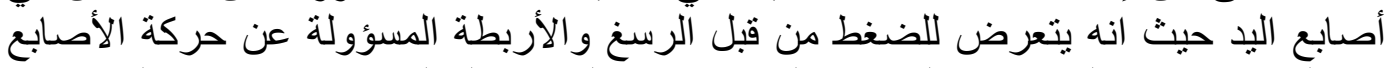

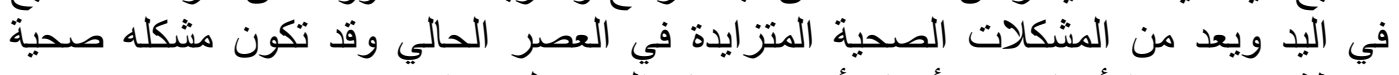

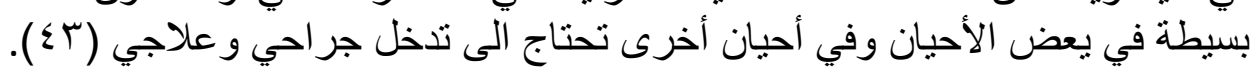


متلازمة روئة الحاسب: Computer Vision Syndrome

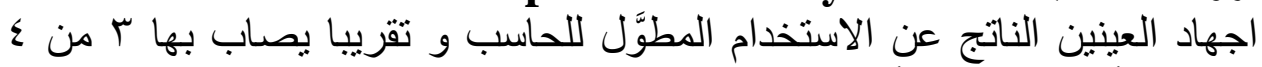
أثخاص يعملون أمام الحاسب لأوقات طويلة ( ؟ ؟).

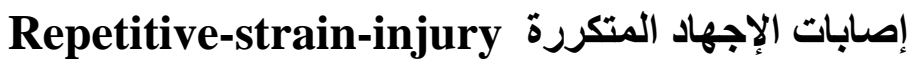

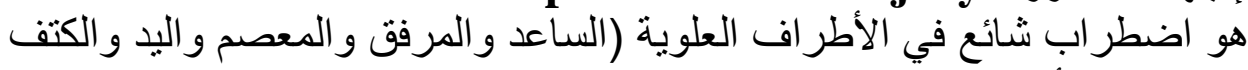

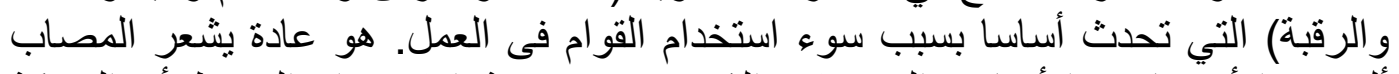

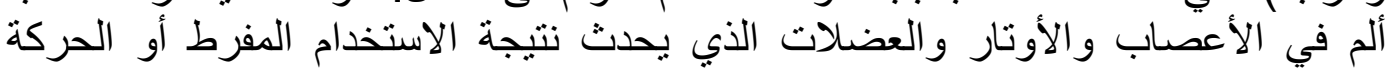

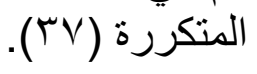

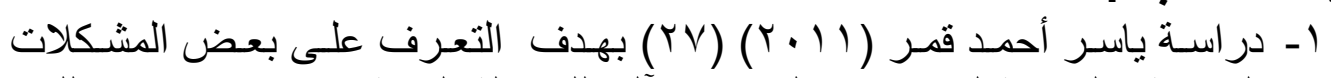

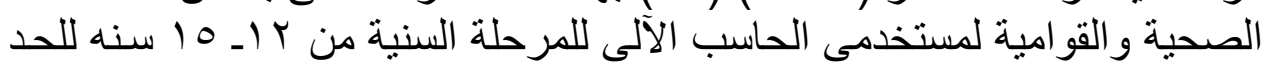

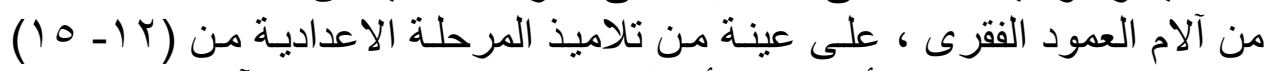

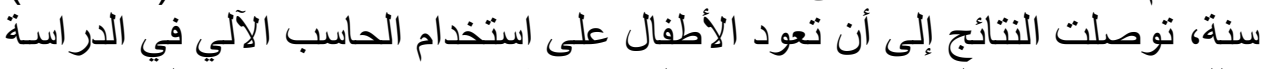

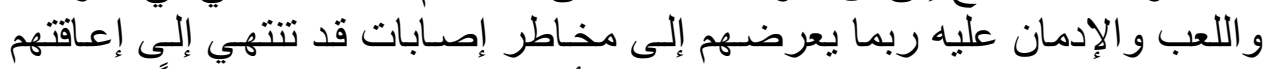

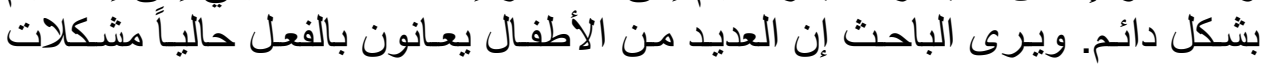

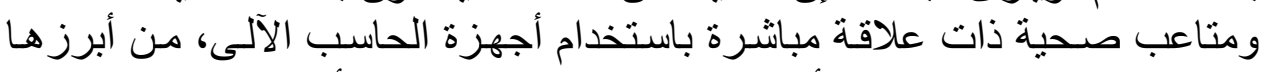

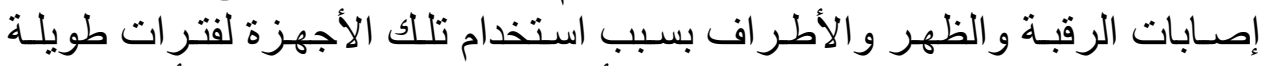

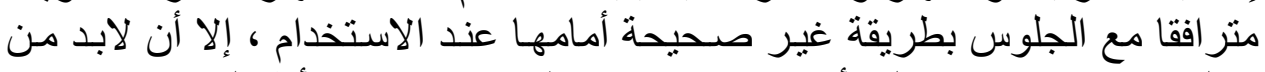

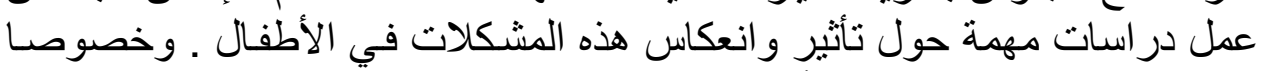

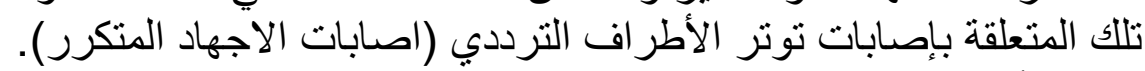

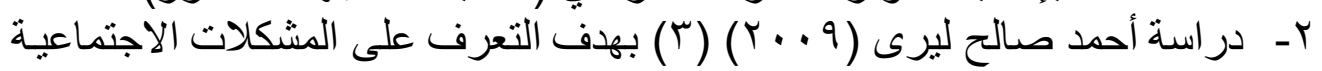

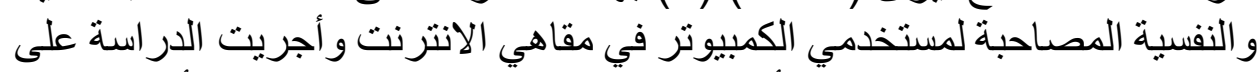

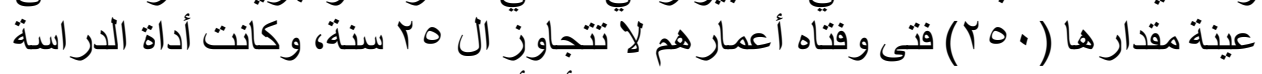

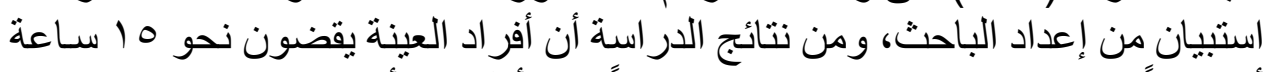

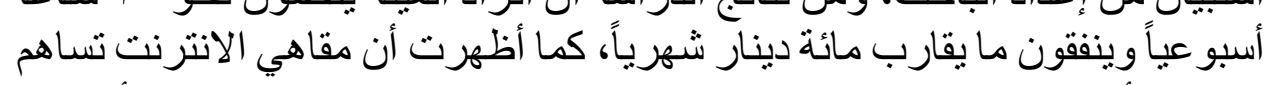

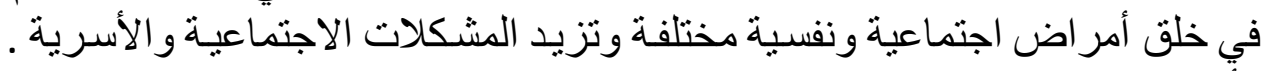

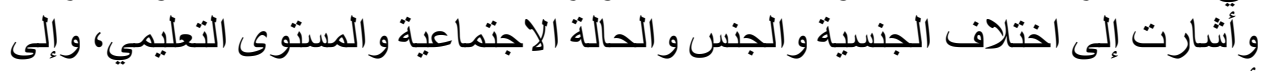

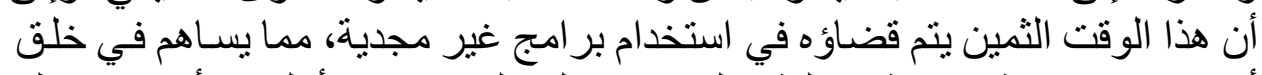

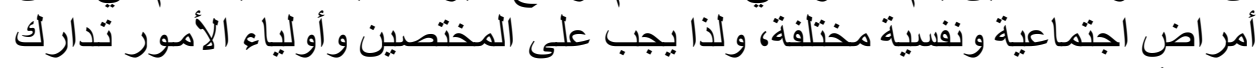
هذه الأخطار .

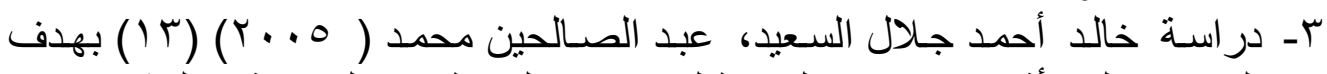

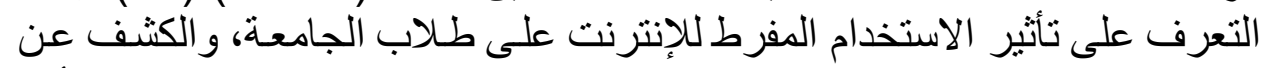

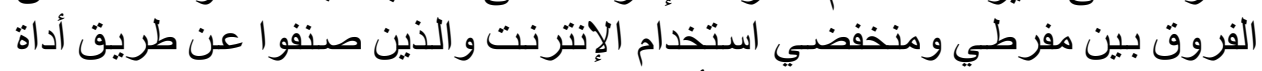

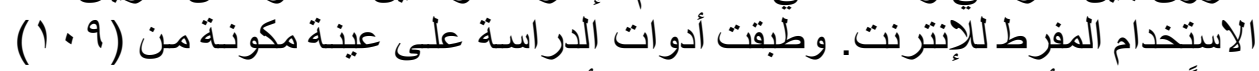

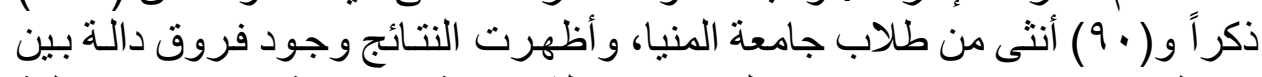

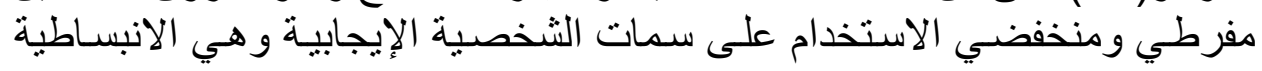


و العدو انية وتأكيد الذات و البحث الحسي، و على سمات الثخصية السلبية وهي توهم

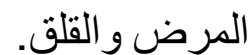

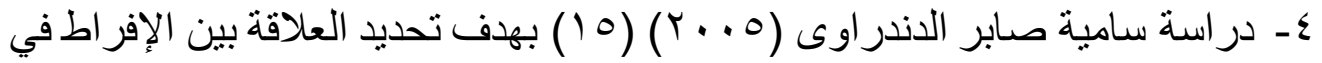

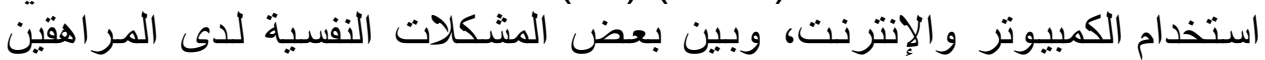

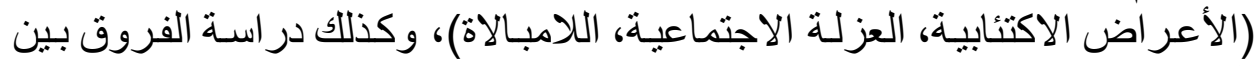

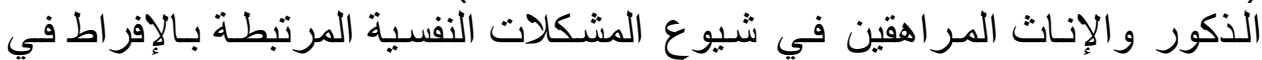

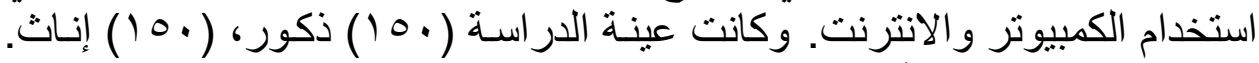

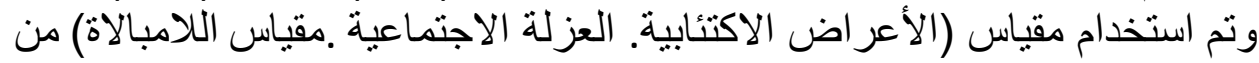

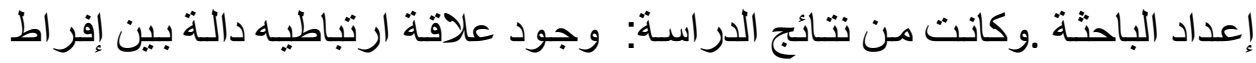

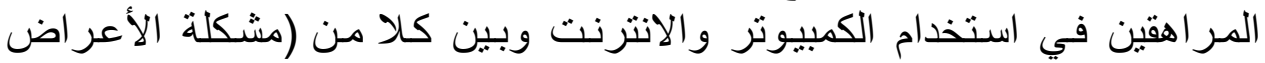

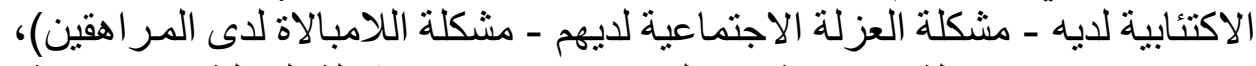

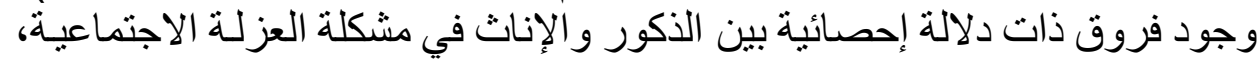
عدم وجود فروق ذات دلالة إحصائية بين الذكور و الإناث في مشكلة الاكتئاب

و واللامبالاة.

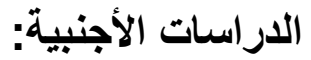

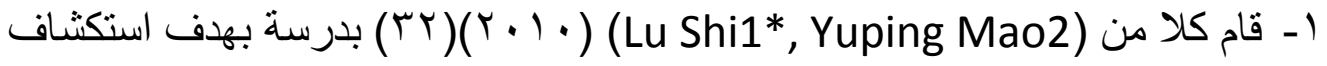

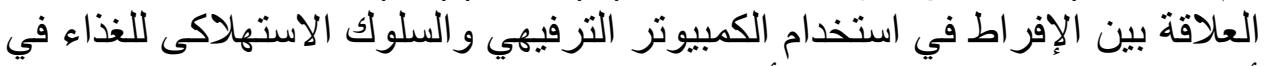

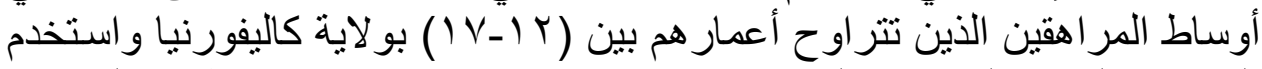

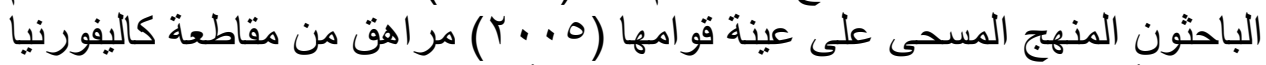

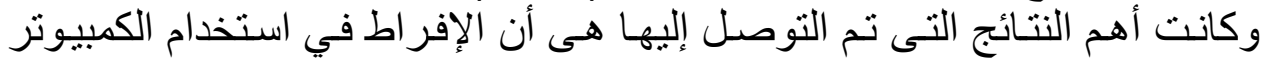

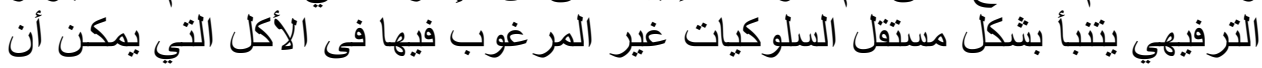
تؤدي إلى زيادة الوزن و والسمنة

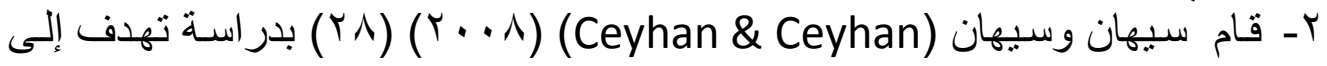

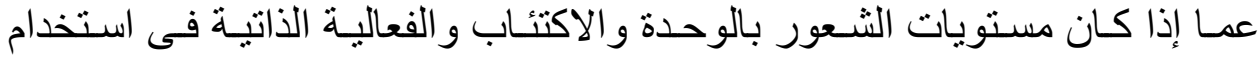

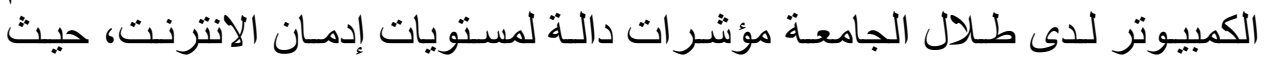

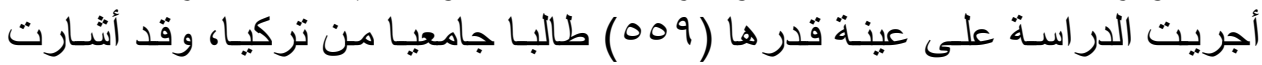

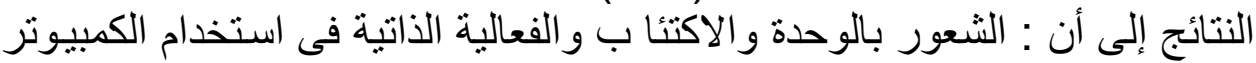

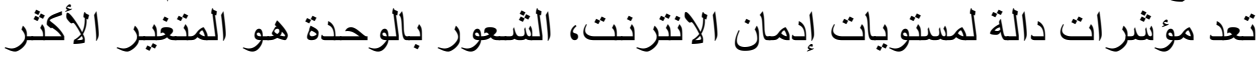

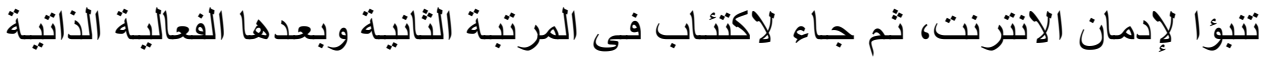

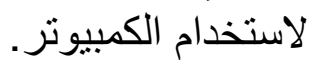

rا

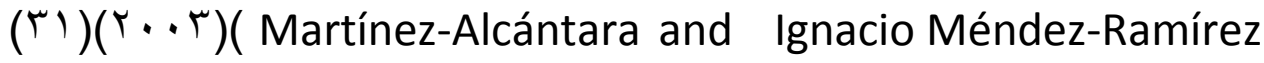

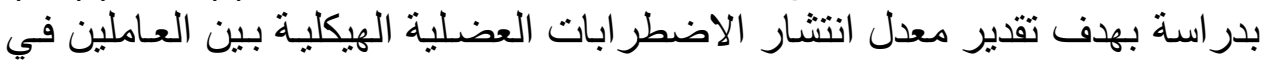

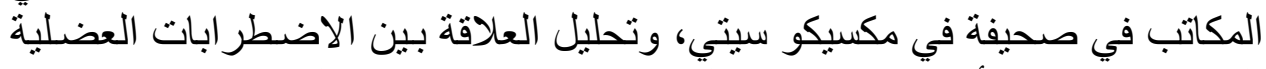

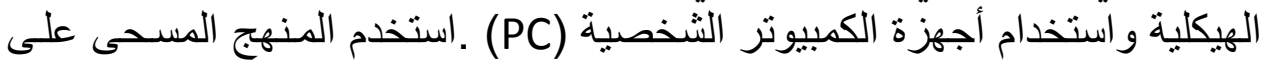

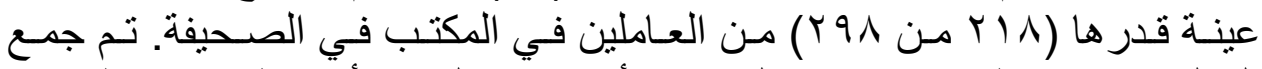

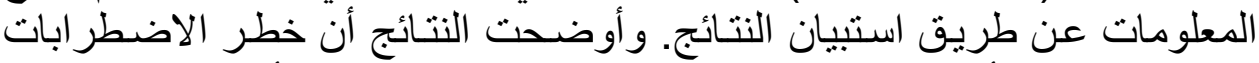

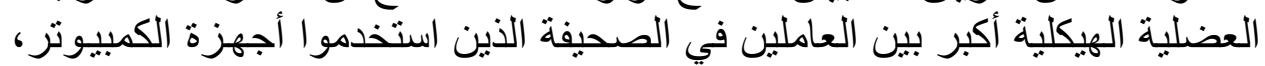


و الذين يقومون بأعمال التحرير، و أظهرت نتائج دراستنا أن استخدام PC زاد الاد خطر

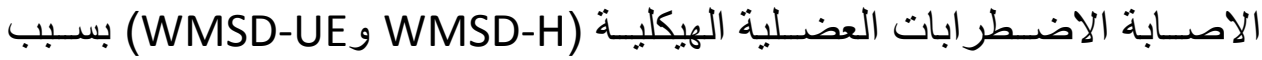

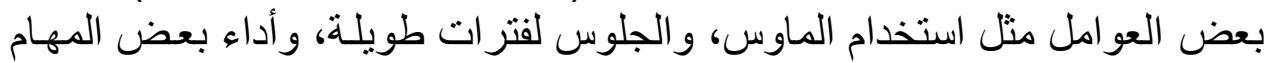
PC و والعو امل النفسية و الاجتماعية.

التعليق على الاراسات السابقة: 1 - اتفقت جميع الدراسات السابقة على استخدام المنهج الوصفى.

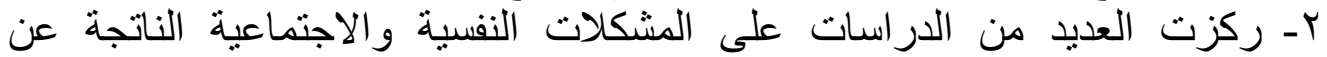

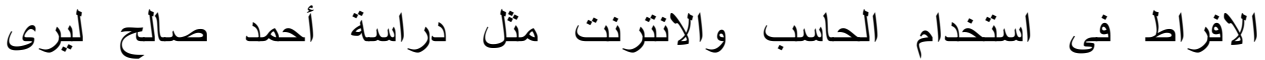

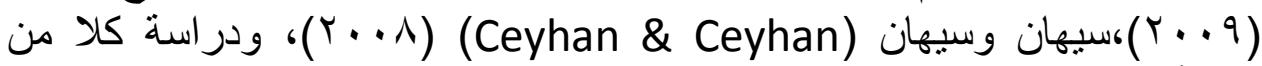

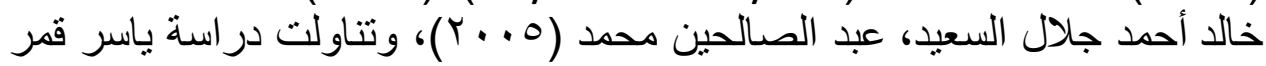

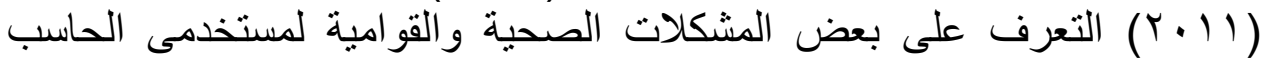

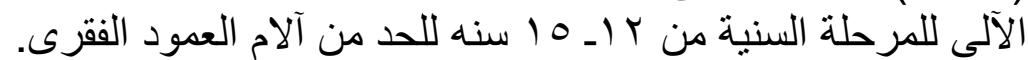

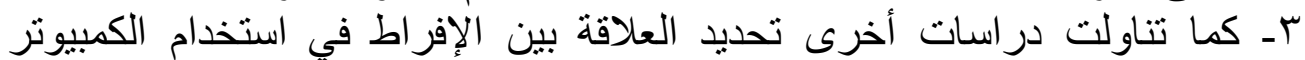

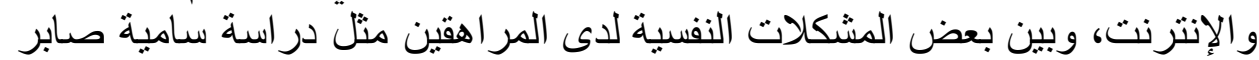

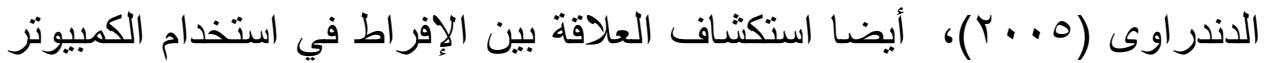

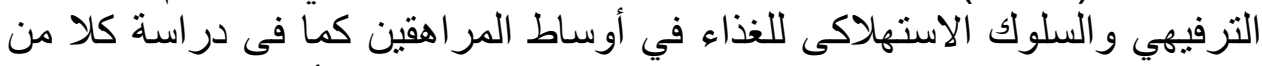

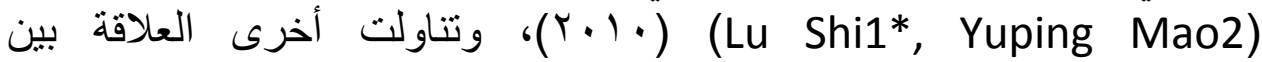

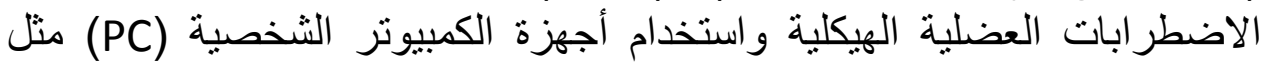
Luis Ortiz-Hernández, Silvia Tamez-González, Susana ) دراسة

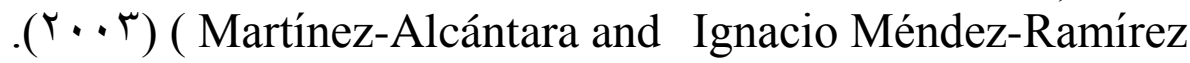

$$
\begin{aligned}
& \text { الاستفادة من الاراسات السابقة : }
\end{aligned}
$$

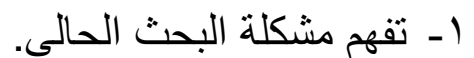

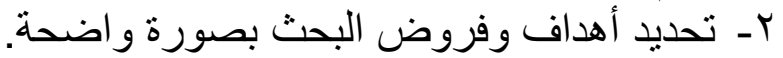

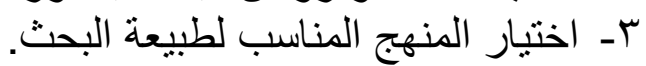

$$
\begin{aligned}
& \text { ع ـ اختيار نوع وحجم العينة. } \\
& \text { هـ تحديد أنسب أدو ات جمع البيانات. }
\end{aligned}
$$

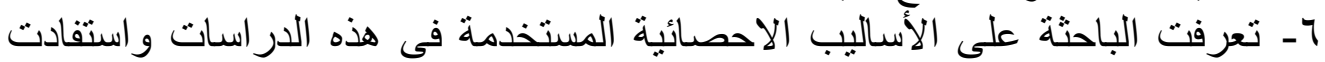$$
\text { من بعضها فى در استها الحالية. }
$$

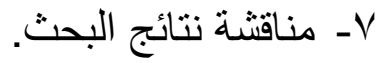

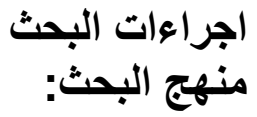

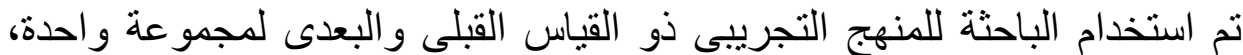

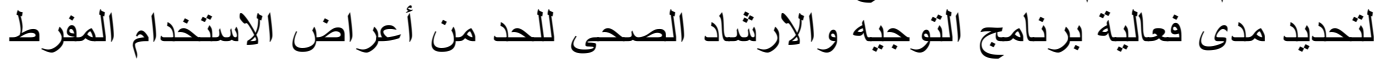
للحاسب الآلى للمر اهقين.

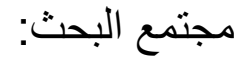


تم تحديد مجتمع البحث بالطريقة العمدية من المراهين الزين الذكور بالمرحلة الثانوية

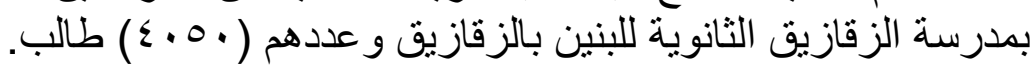

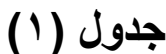

\section{توصيف مجتمع البحث}

\begin{tabular}{|c|c|c|c|c|c|c|}
\hline \multicolumn{2}{|c|}{ العينة الاستطلاعية } & \multicolumn{2}{|c|}{ العينة الأساسية } & \multicolumn{2}{|c|}{ عينة البحث الكلية } & \multirow{2}{*}{ البحتث } \\
\hline النسبة \% & العدد & النسبة \% & العدد & النسبة \% & العدد & \\
\hline$\% \cdot$, YO & 1. & $\% \cdot, 99$ & $\varepsilon$. & $\% 1, Y \leq$ & 0. & $\varepsilon .0$. \\
\hline
\end{tabular}

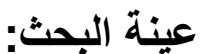

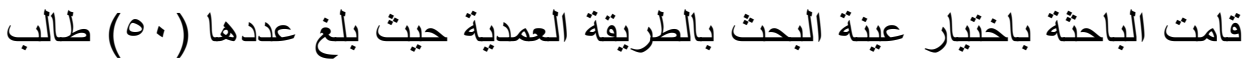

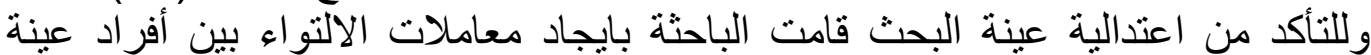
البحث فى متغيرات (السن ـ الطول ـ الوزن ـ الذكاء). و الجدول التالى يوضح ذلاءت اللك.

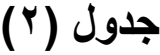

$$
\text { تجانس عينة البحث فى (السن - الطول - الوزن - الأكاء ) }
$$

\begin{tabular}{|c|c|c|c|c|c|}
\hline معامل الالتو اء & الالمعيارى & الوسيط & المتوسط & وحدة القياس & المتغير ات \\
\hline $1,19$. & $7, I T Y$ & $199, \ldots$ & $r \cdot 1, \varepsilon T r$ & شهر & السن \\
\hline., 079 & $T, \Lambda I Y$ & $179,0 \ldots$ & $T V \cdot, \cdot T r$ & سم & الطول \\
\hline - & $\Gamma, T V \varepsilon$ & $79, \ldots$ & $T \Lambda, Y \mu T$ & كيلوجر ام & الوزن \\
\hline$\cdot, \tau \cdot T-$ & $\Gamma, \varepsilon r$ & $01, \ldots$ & $0 ., 70$ & درجة & الذكاء \\
\hline
\end{tabular}

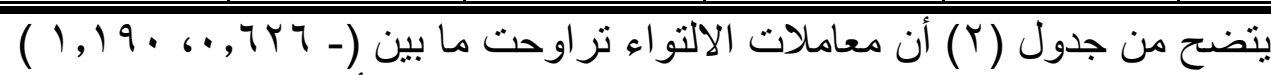

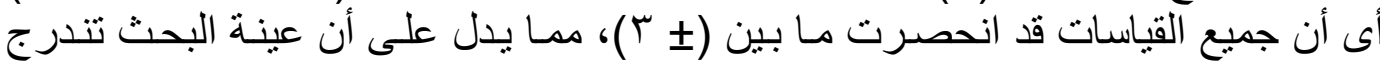

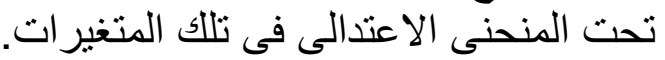

استخدمت الباحثة الأدو ات التالية لجمع البيانات الخاصة بهذا البحث وكانت كالتالى:

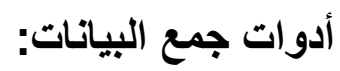

ه هاز الريستامير لقياس الطول "بالسنتيميتر".

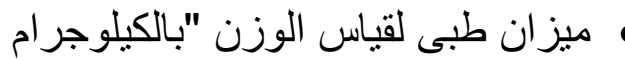

$$
\begin{aligned}
& \text { عدد (• ع ) جهاز كمبيوتر. }
\end{aligned}
$$

$$
\text { ثانيا : الاستمارات والاختبارات والمقاييس }
$$

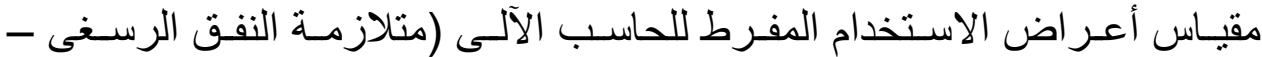

متلازمة رؤية الحاسب الآلى - إصابات الاجهاد المتكرر) ملحق (r). 


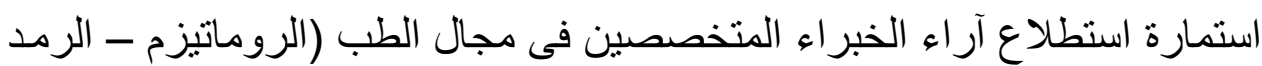

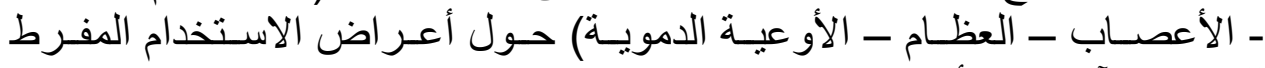

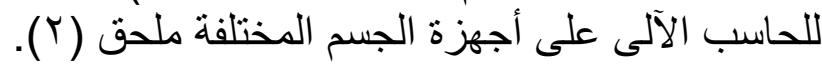

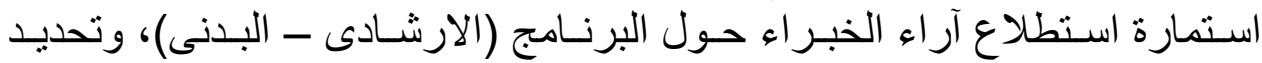

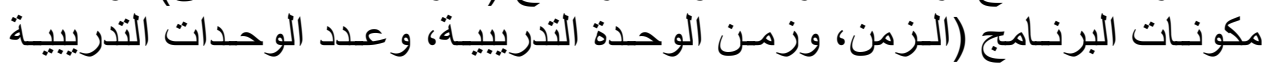

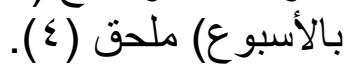

اختبار الذكاء من إعداد أحمد ذكي صالح لقياس القدرة العقلية العامة ملحق (ج).

\section{مقياس أعراض الاستخدام المفرط للحاسب الآلى ملحق (بّ):}

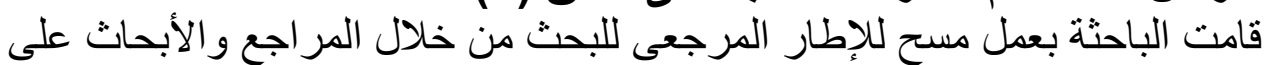

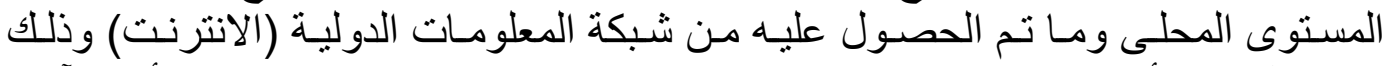

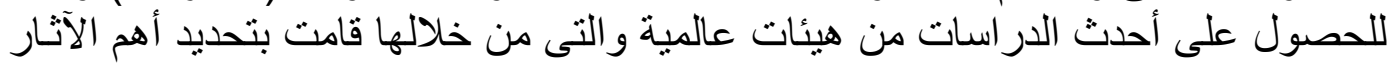

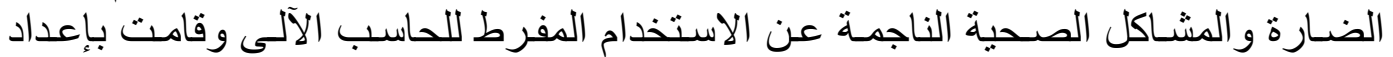

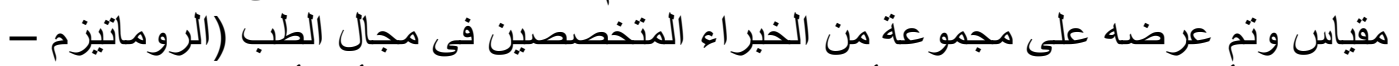

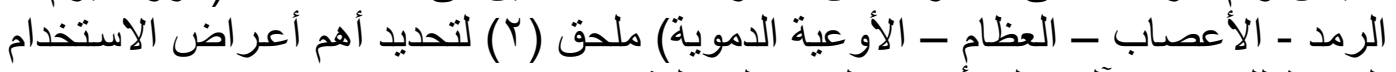
المفرط للحاسب الآلى على أجهزة الجسم المختلفة.

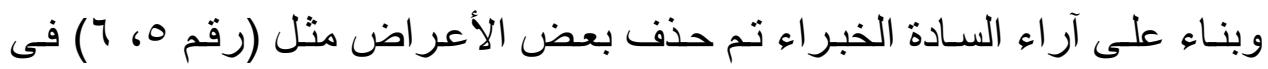

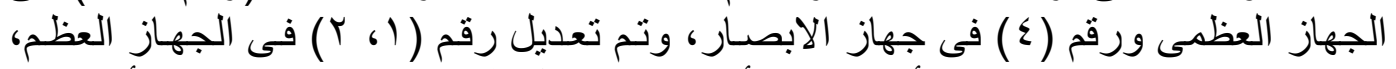

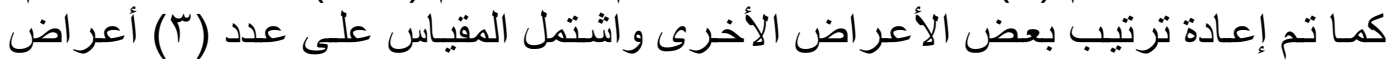

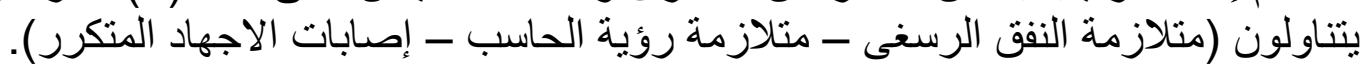

تم حساب صدق مقياس أعر اض الاستخدام المفرط للحاسب الآلى باستخدام عدة

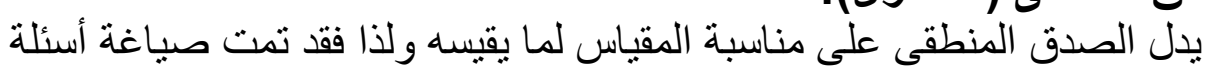

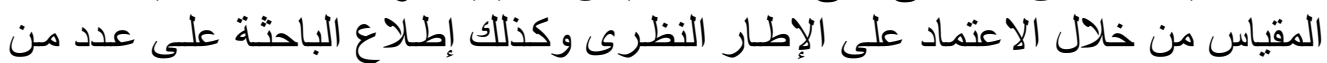

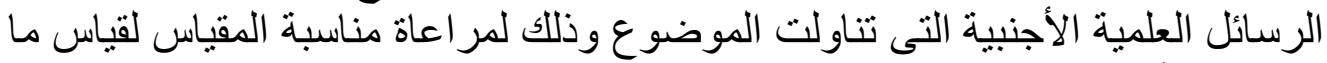

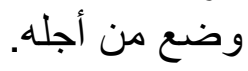

\section{r- بـ المدمين (الظاهرى):}

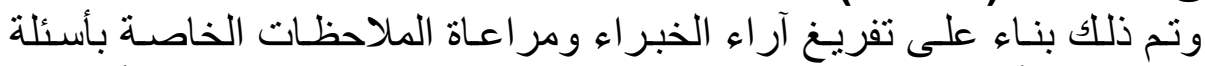

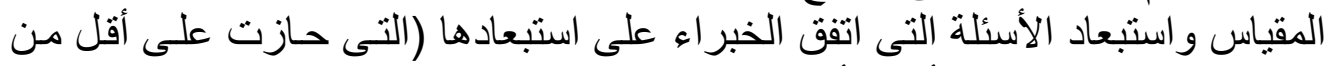

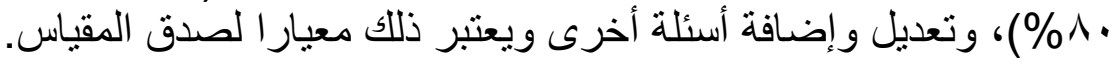




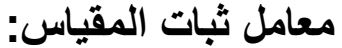

الإيجاد معامل ثبات المقياس قامت الباحثة باستخدام:

1- التجزئة النصفية لإجابات عينة الدراسة الاستطلاعية لأعر اض الاستخدام المفرط

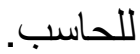

r- طريقة ألفا كرونباخ Alpha" . . و الجدول (r) يوضح ذلك.

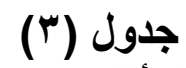

الثبات بالتجزئة النصفية ومعامل ألفا كرونباخ لمقياس أعراض الاستخدام

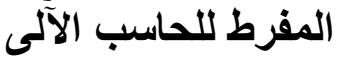

\begin{tabular}{|c|c|c|}
\hline كرونباخ & النصفئة & أعر اض الاستخدام المفرط \\
\hline
\end{tabular}

\begin{tabular}{|c|c|c|}
\hline$\cdot$ & $\cdot, 99$. & هل تشعر بألم فى مفاصل الأصـابع والرسخ و الكوع \\
\hline$\cdot, 9 \vee \vee$ & $\cdot, q \wedge \vee$ & 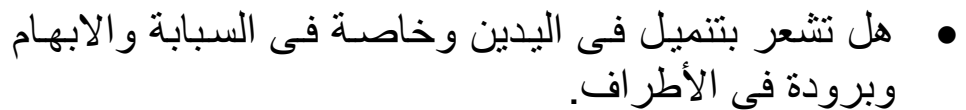 \\
\hline$\cdot, 919$ & $\cdot, 910$ & القبض علـ تشـعر الأشياء. \\
\hline, 99. & $\cdot, 997$ & هل يحدث تورم لليد أحيانا وتصلبها \\
\hline
\end{tabular}

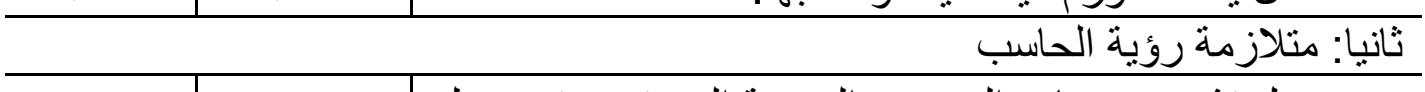

\begin{tabular}{|c|c|c|}
\hline ש79 & $\cdot, 909$ & 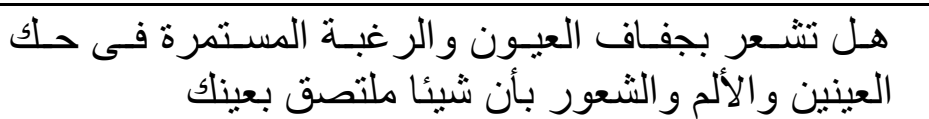 \\
\hline$\cdot, 9 \times 1$ & $\cdot, 974$ & انخفاض حدة الرؤية \\
\hline$\cdot, 971$ & $\cdot, 9 \vee \Gamma$ & الزغللة \\
\hline., $9 \vee \mu$ & $\cdot, 9 \wedge \mu$ & هل تشعر بضبابية فى الرؤية. \\
\hline$\cdot, 9 \wedge 1$ & $\cdot, 904$ & 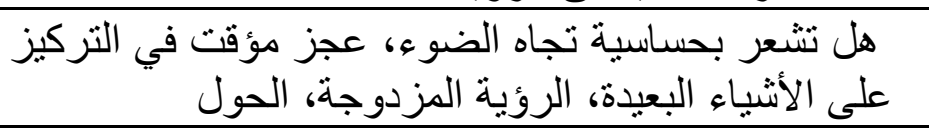 \\
\hline$\cdot, 9 \times 1$ &., 970 & هل تشعر بصداع. \\
\hline
\end{tabular}

ثالثا: إصابات الاجهاد المنكررة

\begin{tabular}{|c|c|c|}
\hline$\cdot, 971$ & $\cdot 974$ & هل تشعر بألم أسفل الظهر \\
\hline .,9人r & $\cdot, 9 \vee 9$ & هل تشعر بألم فى الرقبة و الكتفين. \\
\hline$\cdot, 9 \wedge \mathrm{V}$ & $\cdot, 991$ & هل تشعر بألم حاد فى الجزء العلوى من الظهر \\
\hline
\end{tabular}

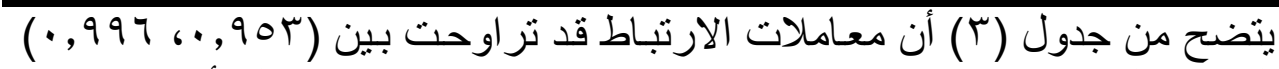

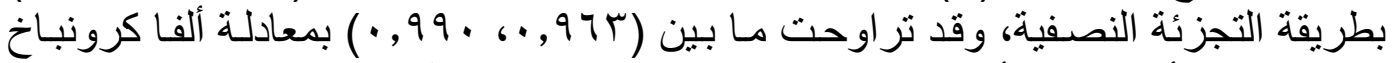

مما يدل على أن لمقياس أعر اض الاستخدام المفرط للحاسب الآلى ذات معامل ثبات عالى بهاتي. 


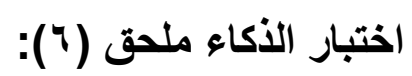

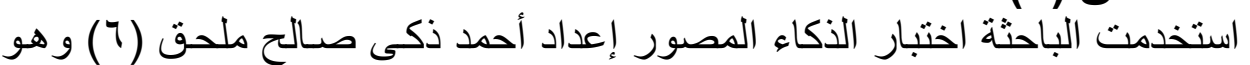

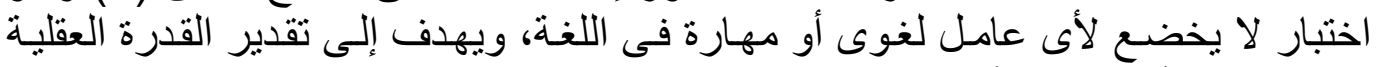
العامة لاى الأفراد فى الأعمار من سن الثامنة إلى السابعة عشر وما بعدها.

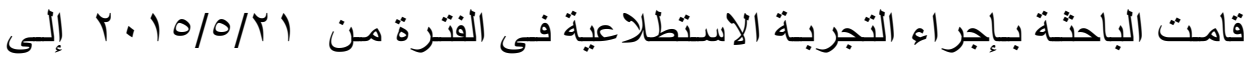

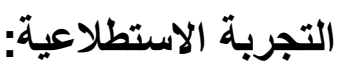

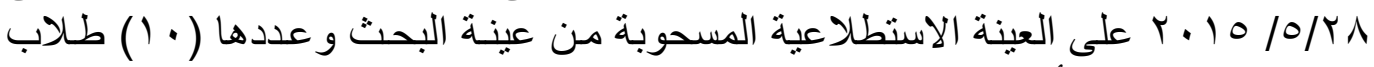

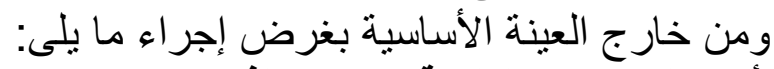

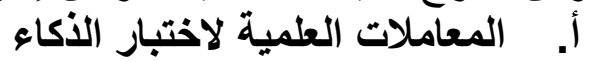

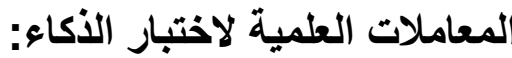

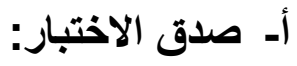

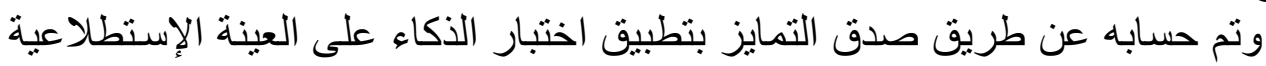

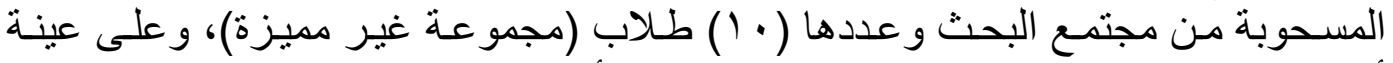

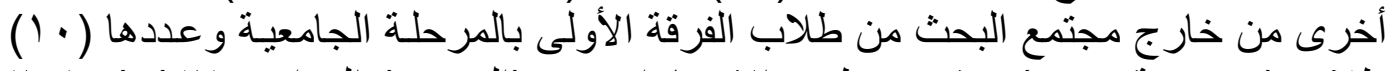

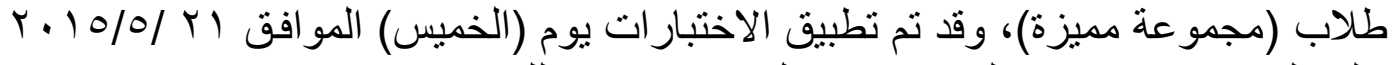

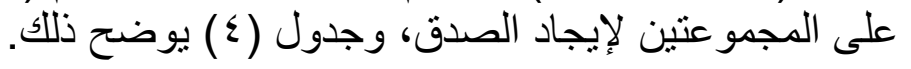

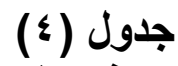

دلالة الفروق بين المجموعتين المميزة وغير المميزة فى اختبار الأكاء (صدق التمايز) ن نان

\begin{tabular}{|c|c|c|c|c|c|c|}
\hline \multirow{2}{*}{ " } & \multirow{2}{*}{ المترسطين } & \multicolumn{2}{|c|}{ المجموعة غير المميزة } & \multicolumn{2}{|c|}{ المجمو عة المميزة } & \multirow{2}{*}{ الإختبار } \\
\hline & & $\varepsilon \pm$ & 5 & $\varepsilon \pm$ & 5 & \\
\hline $11, Y \wedge$ & $1 \Gamma, \wedge \Lambda$ & $r, V T$ & $01, r \mu$ & $r, \leqslant 0$ & $70, Y 1$ & الذكاء \\
\hline
\end{tabular}

يتضح من جدول ( ) وجود فروق دالـة إحصائيا بين المجمو عتين المميزة وغير المباء

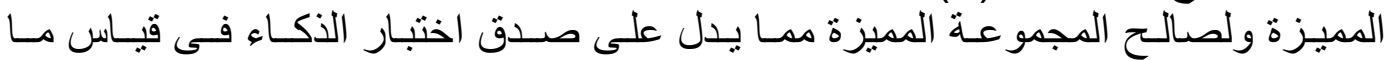

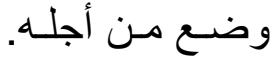

قامت الباحثة بايجاد معامل الثبات باستخدام طريقة تطبيق الاختبار و إعادة تطبيقه الإنه Test - Retest

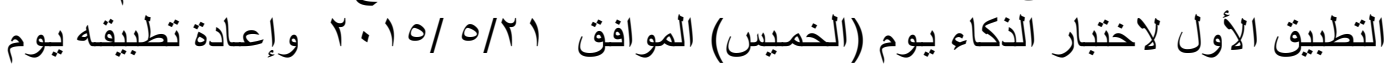

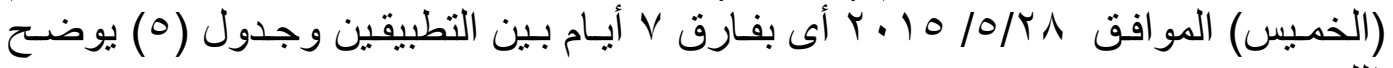


جدول (0)

معامل الارتباط بين التطبيقين الأول والثانى لاختبار الأكاء (الثبات). 1.

\begin{tabular}{|c|c|c|c|c|c|}
\hline \multirow{2}{*}{ قيمة ر } & \multicolumn{2}{|c|}{ التطبيق الثانى } & \multicolumn{2}{|c|}{ التطبيق الأول } & \multirow{2}{*}{ الإختبار } \\
\hline & $\varepsilon \pm$ & 5 & $\varepsilon \pm$ & 5 & \\
\hline$\cdot, \Lambda \mid r$ & $r, Y \wedge$ & $0 ., Y V$ & $r, V T$ & TוT, & الذكاء \\
\hline
\end{tabular}

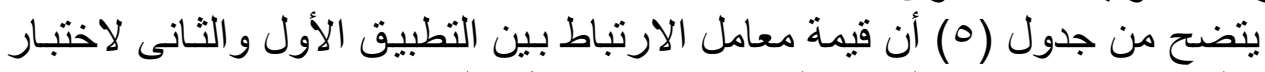

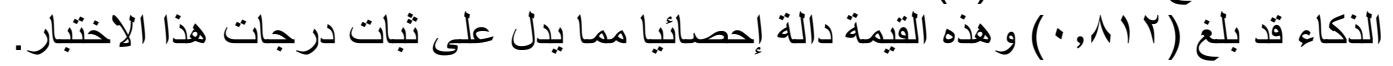
ثالثا: برنامج الارشاد الصحى: ملحق (0)

خطوات بناء (تصميم) برنامج الارشاد الصحى المقترح:

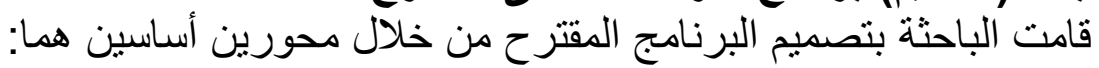
ا ـ الإطار المرجعى للبحث:

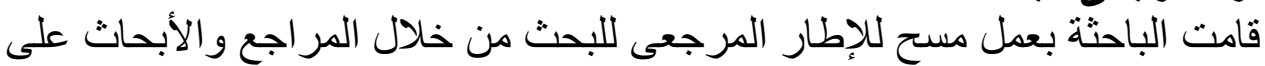

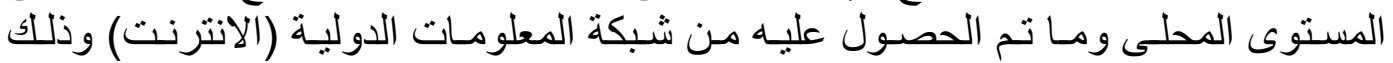

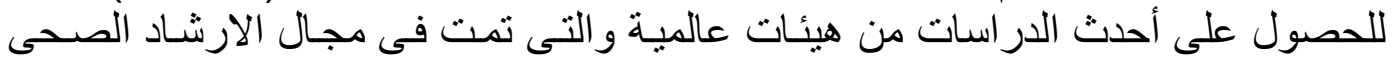

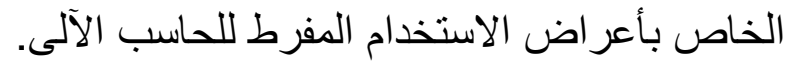

r ـ استمارة استطلاع رأى السادة الخبراء:

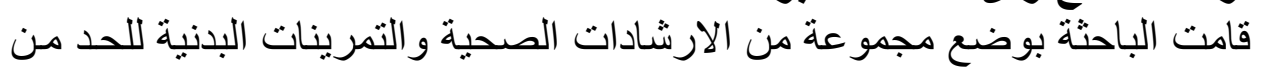

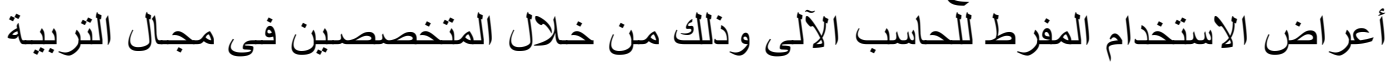

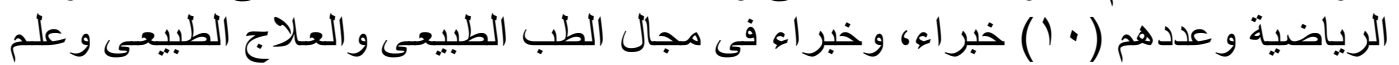

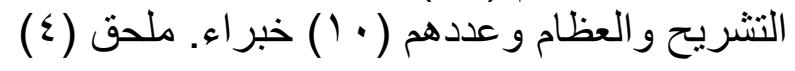

\section{وتم تصميم استمارة للعرض على السادة الخبراء بهدف التعرف على:}

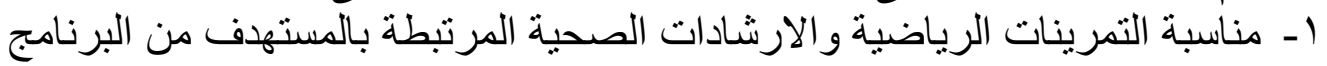

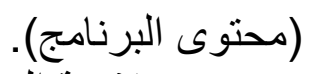

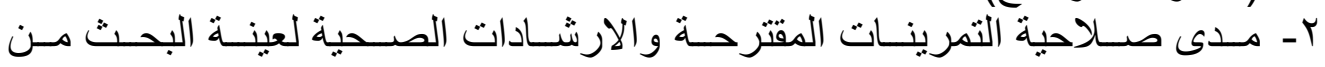
المر اهقين. r- الفترة الزمنية الكلية لتنفيذ البرنامج ومدى مناسبتها للتمرينات المحددة.

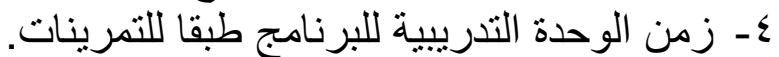

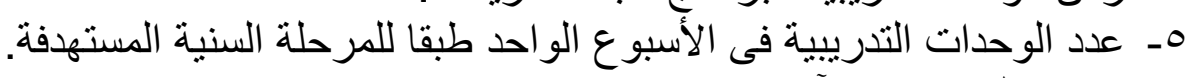

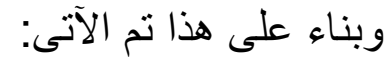

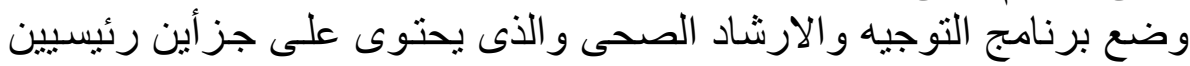

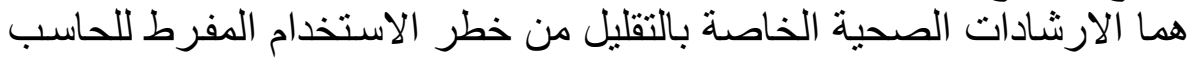

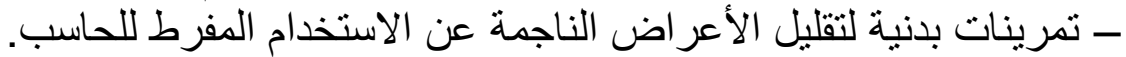

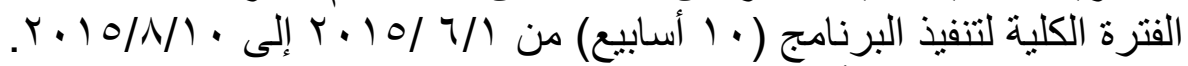

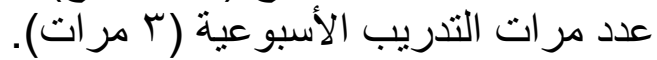


زمن الوحدة التدريبية (• قـ ق).

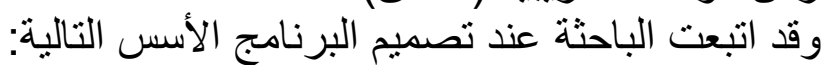

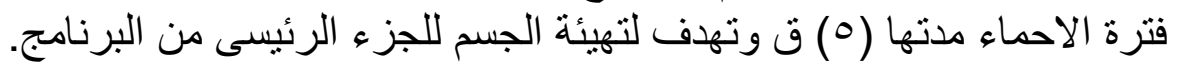

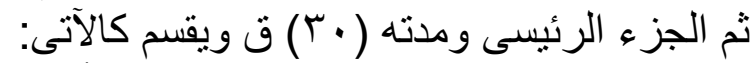

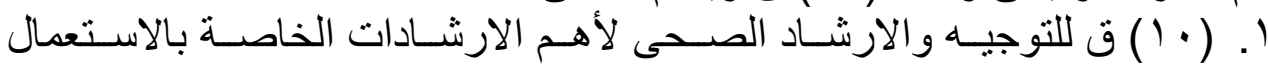

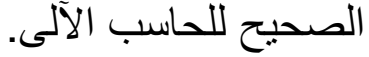

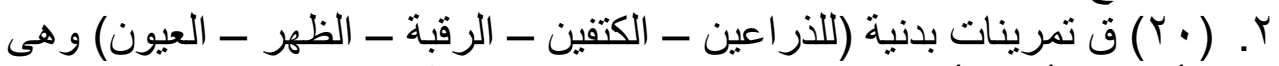

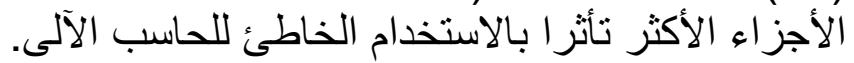

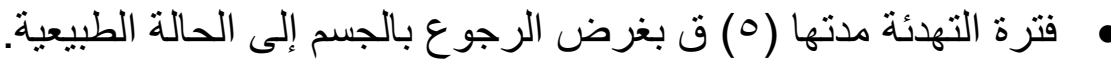
مر اعاة مكونات البرنامج بما يتفق مع تحقيق الهدف منه.

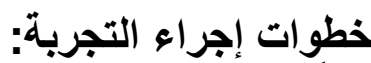

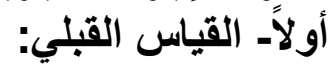

تم إجر اء ألقياسات القبلية يوم السبت المو افق .ب/ 10/ 10 ـ ب من خلال تطبيق مقياس أعر اض الاستخدام المفرط للحاسب الآلى.

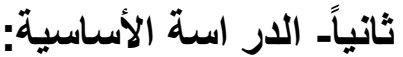

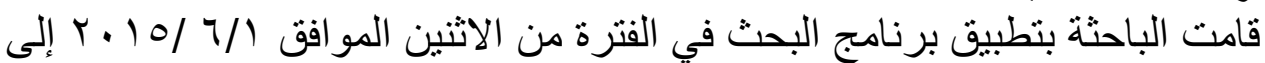

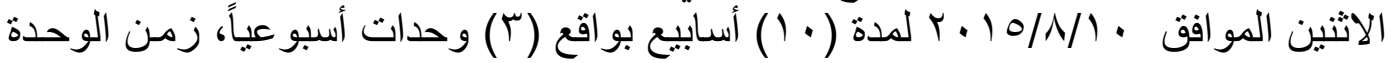
التدرييية (• ع) دقيقة.

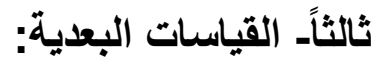

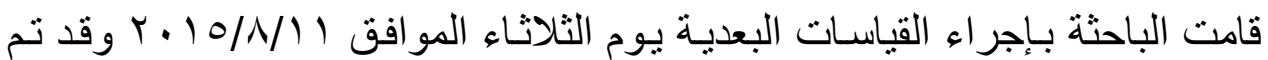
إجر اء القياسات البعدية بنفس الطريقة للقياسات القبلية.

- (المتوسطات الحسابية - الانحراف المعياري - معاملات الالتواء) لايجاد

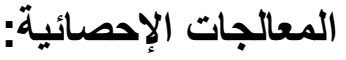

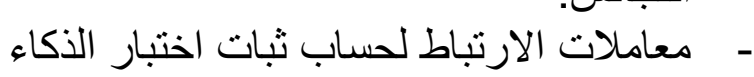

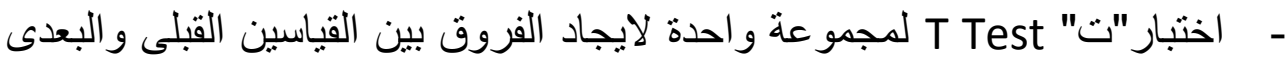

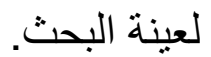

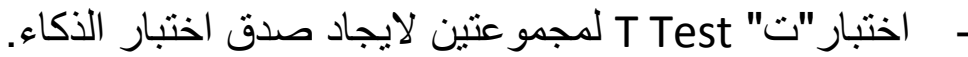
- - التجزئة النصفية ومعامل ألفا كرونباخ لحساب ثبات مقياس ألبات أعراض الاستخدام المفرط للحاسب النفئ ونة 
جدول) (7)

عرض ومناقشة النتائج:

أولا: عرض النتائج:

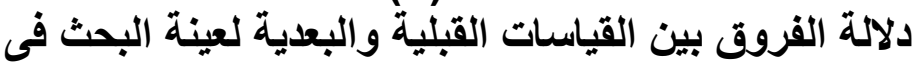

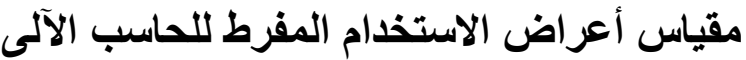

\begin{tabular}{|c|c|c|c|c|c|c|c|c|}
\hline \multirow{2}{*}{ التحسبة } & \multirow{2}{*}{ قيمة "ت" } & \multirow{2}{*}{ م ف } & \multicolumn{2}{|c|}{ بعدي } & \multicolumn{2}{|c|}{ قبلي } & \multirow{2}{*}{ المحاور } & \multirow{2}{*}{ r } \\
\hline & & & $\varepsilon$ & 5 & $\varepsilon$ & 5 & & \\
\hline$\% r \checkmark, \wedge r$ & 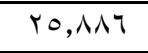 & $r, 10$. & $1, .40$ & 0,11 & 1,110 & A,rr & متلازمة النفق الرسغى & 1 \\
\hline$\%$ \%r,rч & $r_{0, \varepsilon V T}$ & $\varepsilon, r$. & $1, r \leq 9$ & $\wedge, \vee \wedge$ & $1,01$. & $1 r, 9 \lambda$ & متلازمة رؤية الحاسب & r \\
\hline$\% \leqslant 0, \wedge$. & LT, & r, rVo & $\cdot, \vee \vee \wedge ⿻$ & $\varepsilon, \ldots$ & $1, . \vee \vee 9$ & v,ru & الصتكررة & $r$ \\
\hline$\% r v, 7 q$ & $r \leqslant, 919$ & $1 \cdot, V Y$ & 1,179 & IV,VY & 1,049 & $r \wedge, \varepsilon \leqslant$ & المجموع & \\
\hline
\end{tabular}

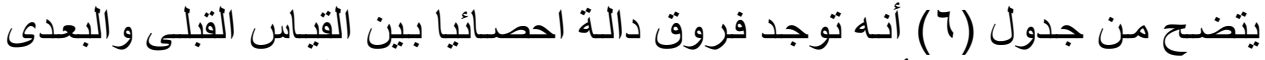

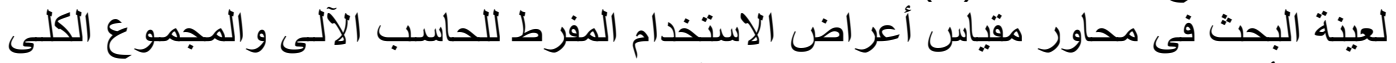

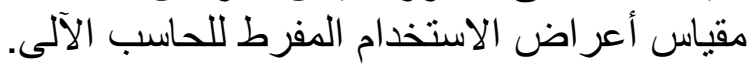

ثانيا: مناقثة النتائج

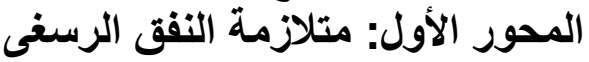

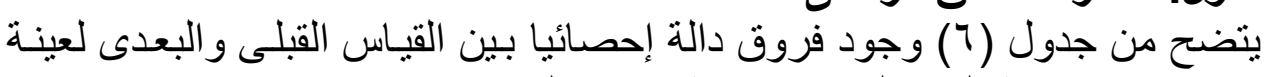

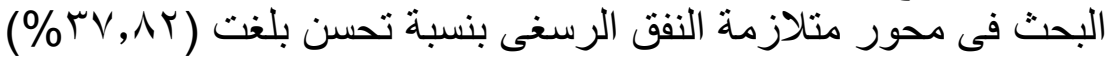

حيث قامت الباحثة بالتركيز على ارشادات صحية لتعديل السلوك الصحى للشخص

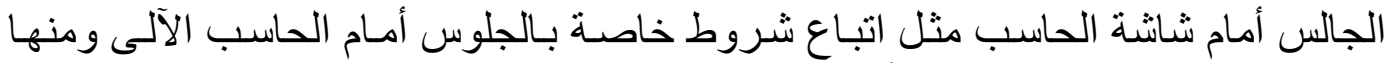

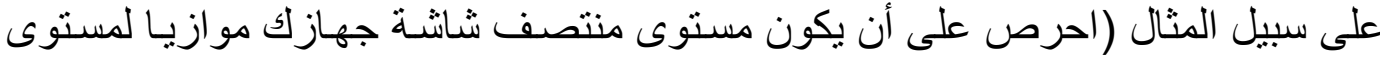

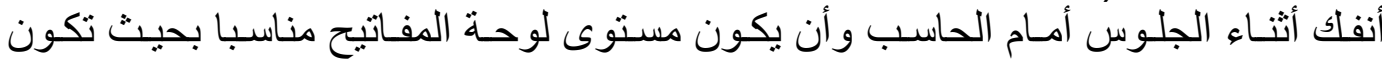

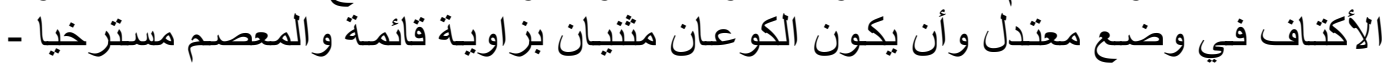

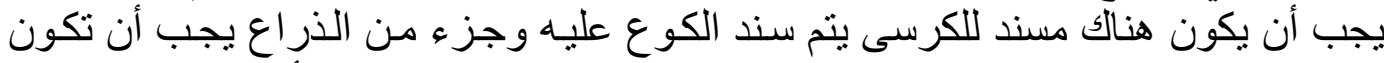

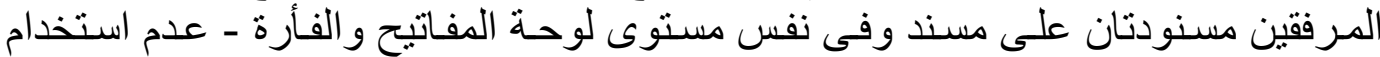

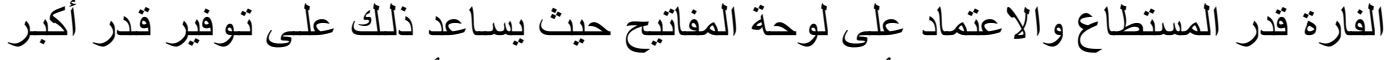

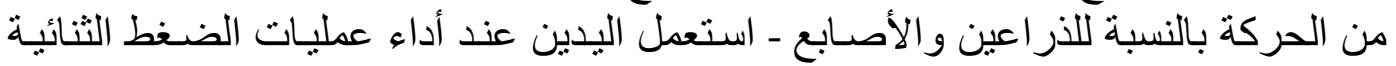

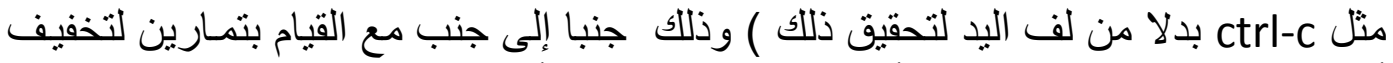

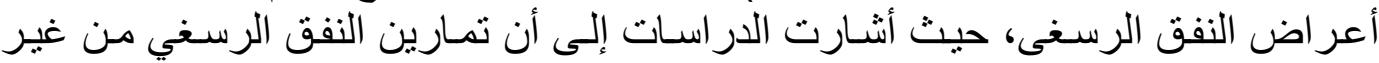

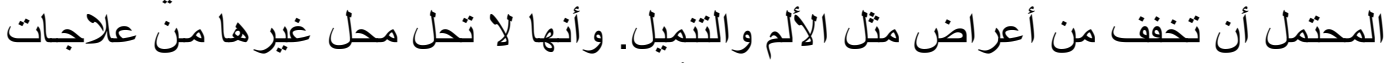

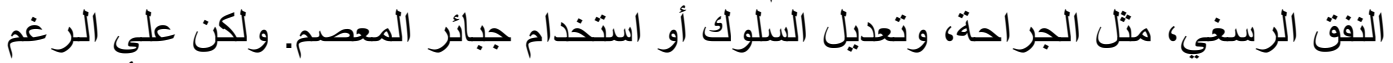

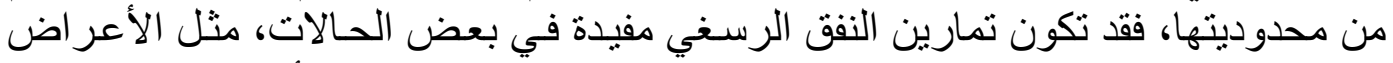

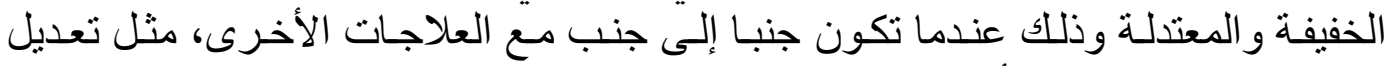
النشاط، التجبير المعصم أو حقن من الستيرويدات القشرية. 
كما يوصي الطبيب بأن تبدأ تمارين النفق الرسغي بشكل تدريجي للتأكد من أنها لا تسبب ضررا أكثر من النفع (بT).

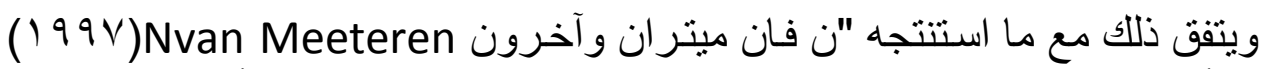

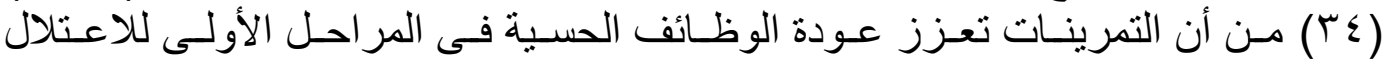

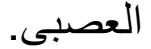

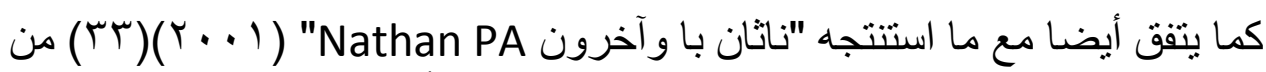

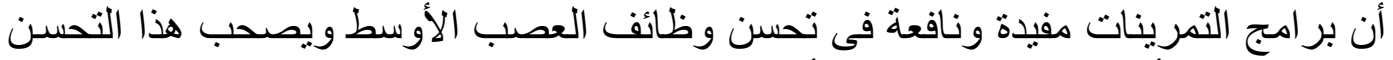
انخفاض فى الأعر اض المصاحبة كالألم.

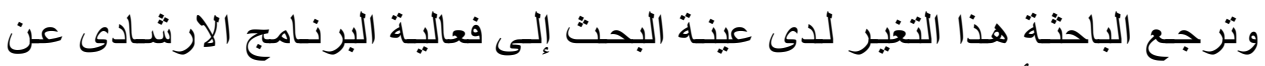

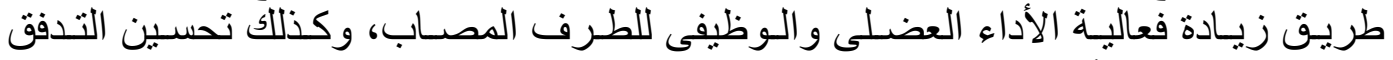

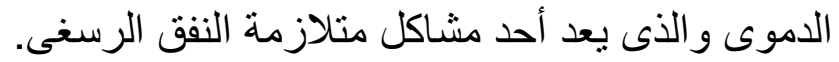

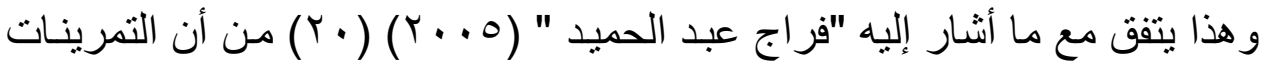

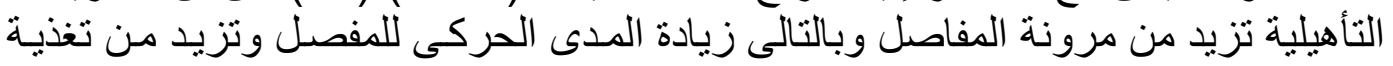
العظام فتنمو بشكل سليم كما تعمل على زيادة مطاطية العضلات العاملة العلى على المفصل.

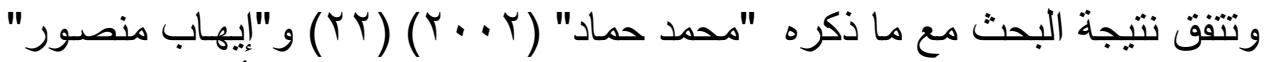

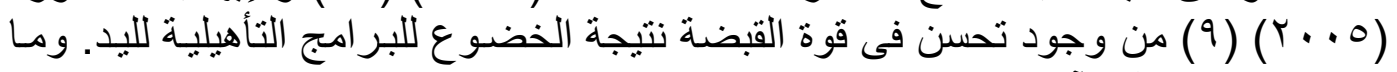

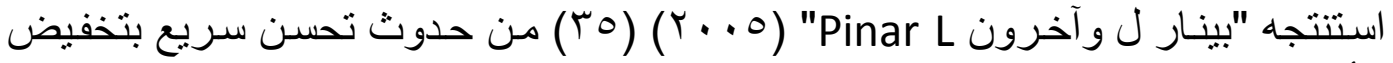
الألم مع ظهور تحسن وظيفى كبير خصوصار لخدى في قوة المسك.

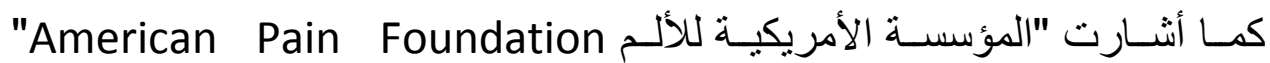

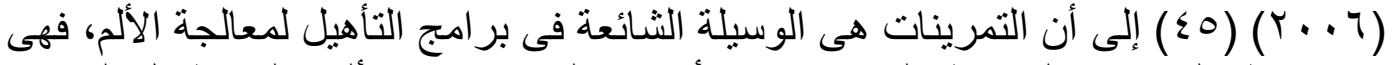

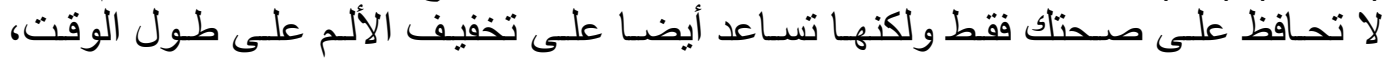

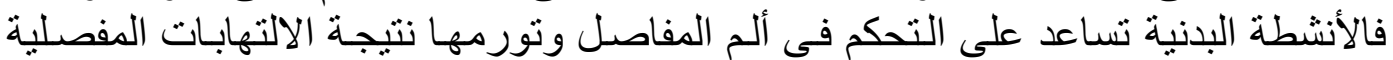
تبعا لقاعدة "إذا لم تستخدمها تخسر هاء".

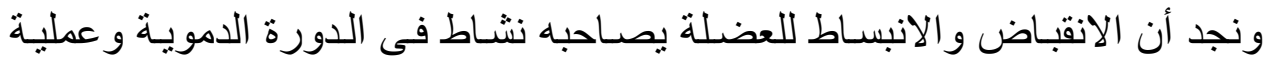

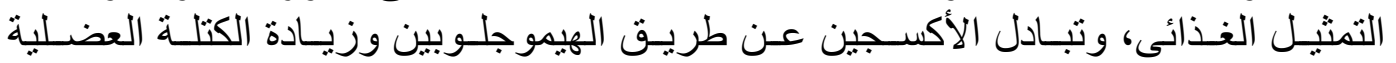

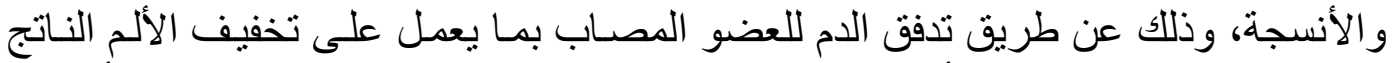

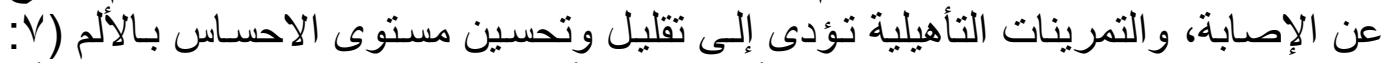

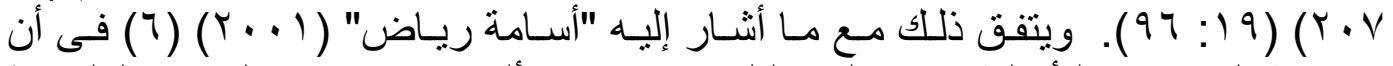

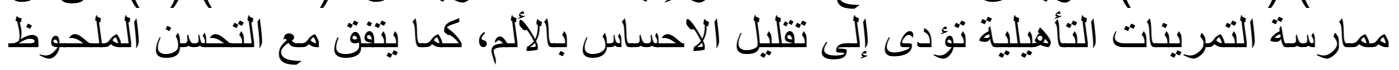
فى تقليل زمن استشفاء مثلازمة النفق الرسنى. 
المحور الثانى: متلازمة روية الحاسب

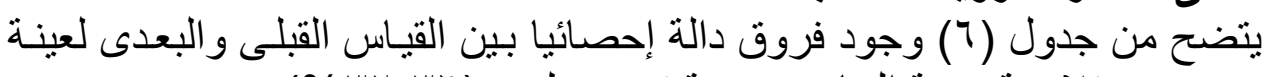

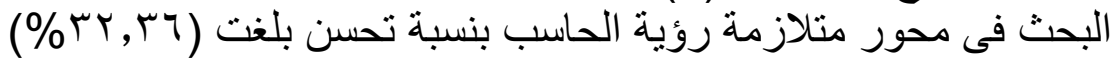

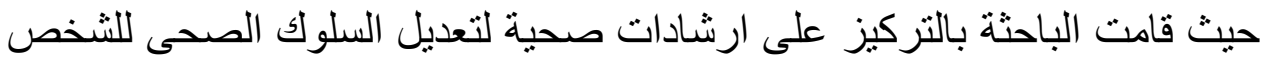

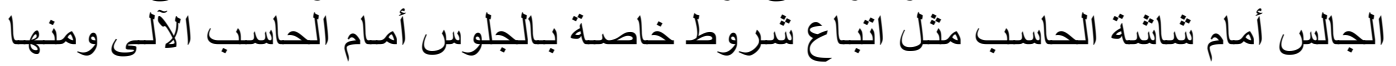

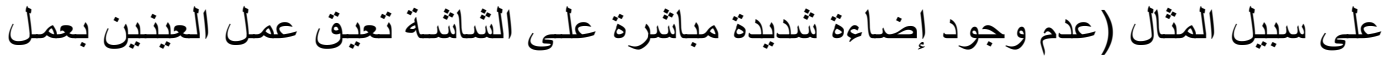

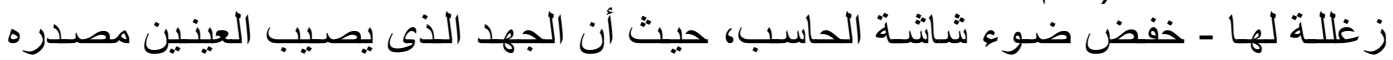

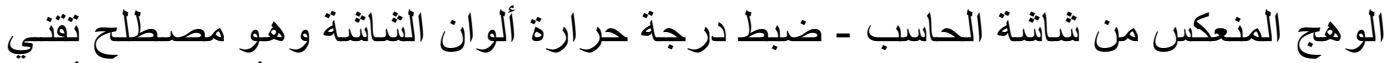

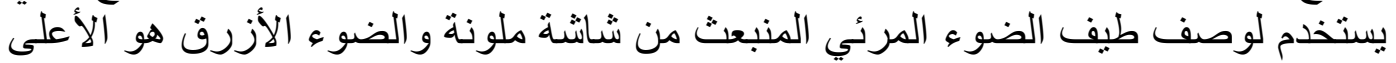

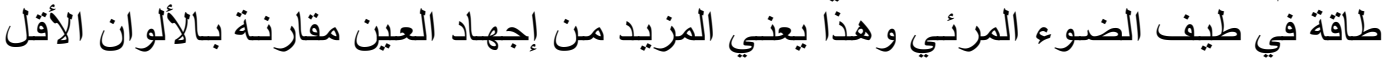

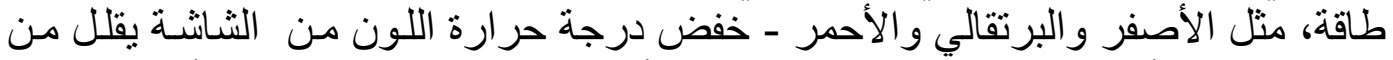

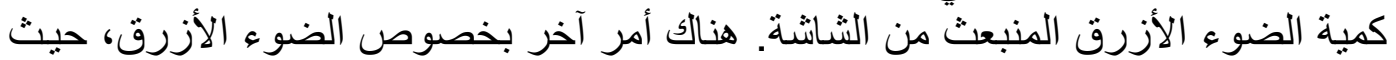

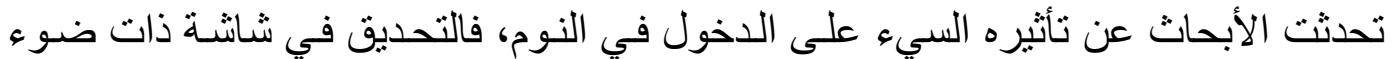

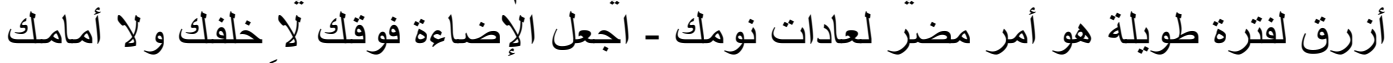

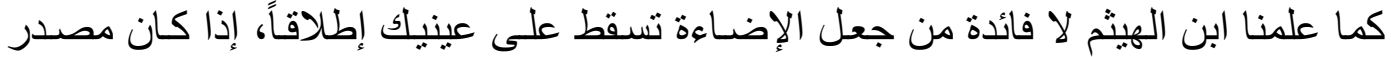

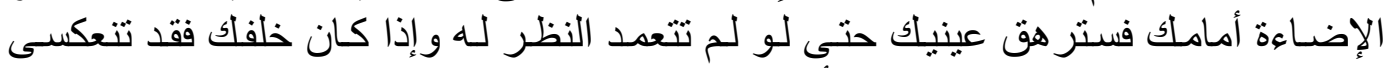

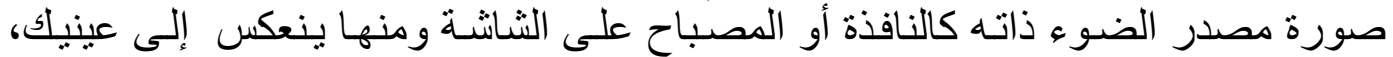

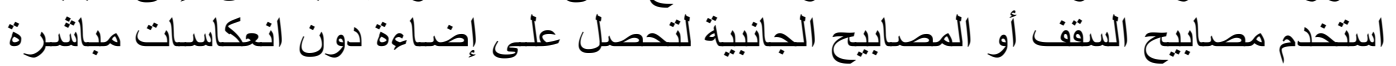

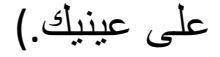

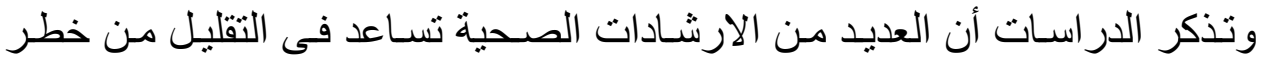

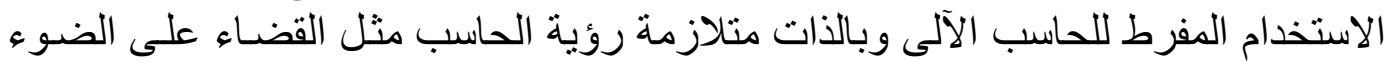

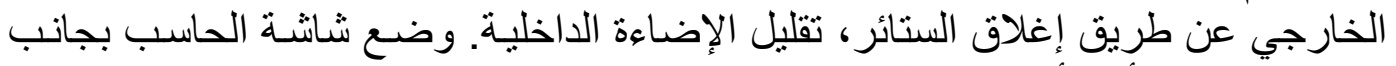
النو افذ، بدلا من أمام أو وراء ذللك.

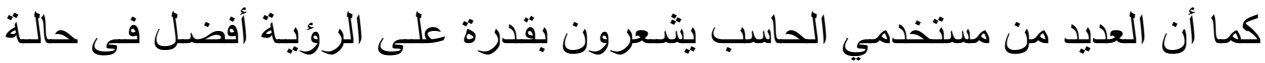

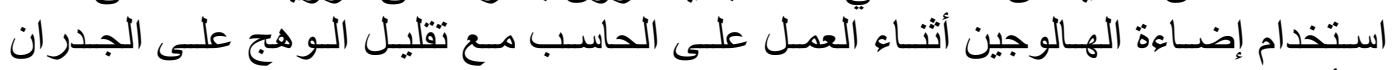

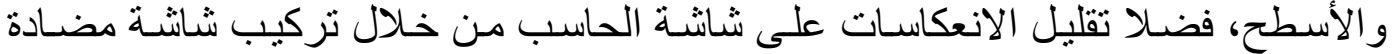

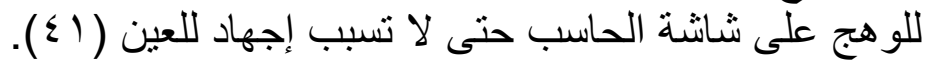

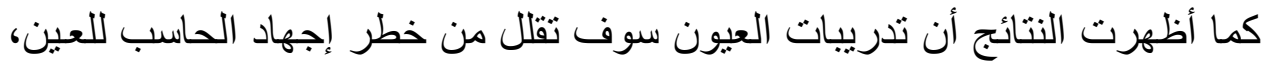

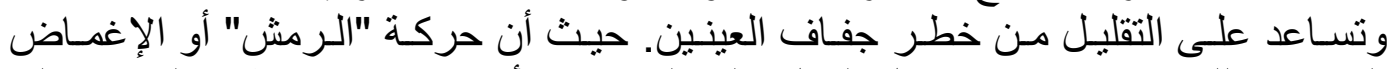

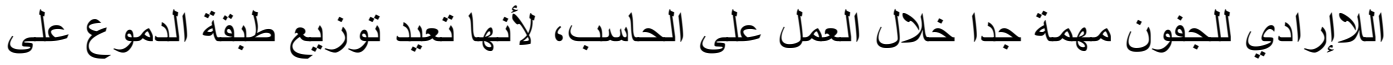

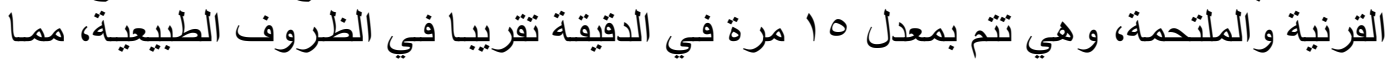
يجنب الثعور بالتهيج و الحرقان و الجفاف.

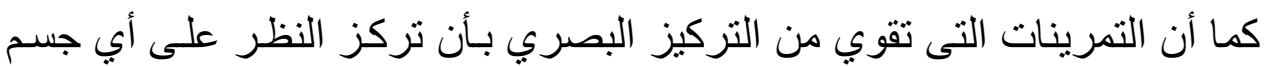

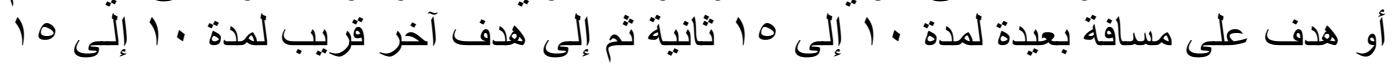




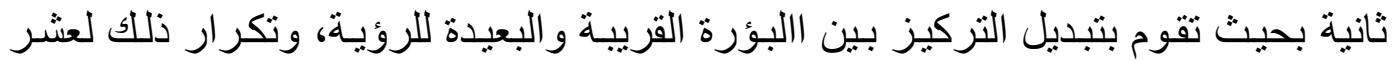

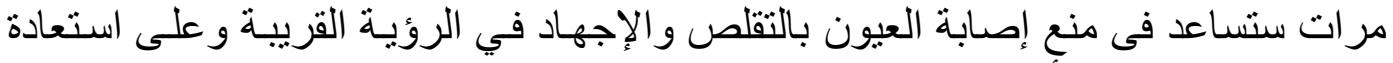

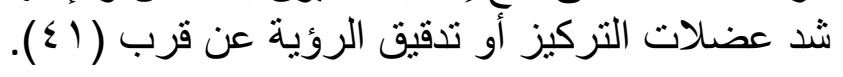

وترى الباحثة أن تهيئة بيئة الممارسة للحاسب الآلى سو اء (مكان وضع الحاسب ـ الاءة)

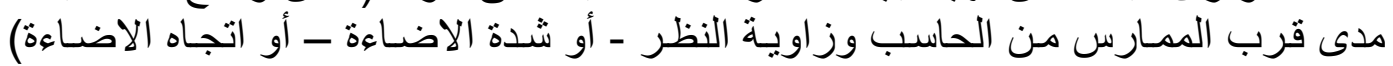

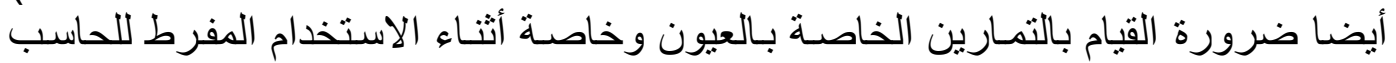

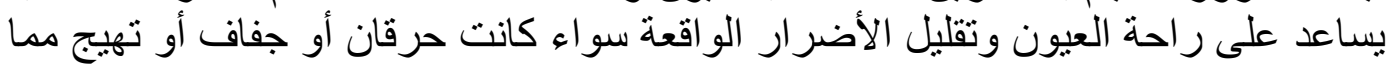
يحافظ على صحة العيون وبقاءها سليمة.

المحور الثالث: إصابات الاجهاد المتكرر

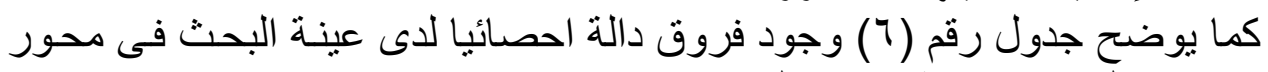

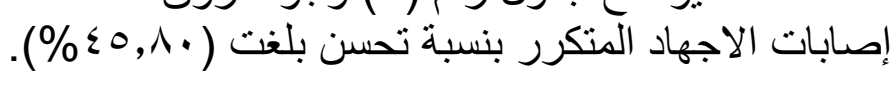

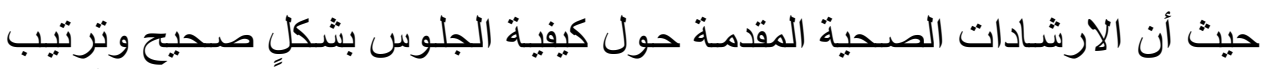

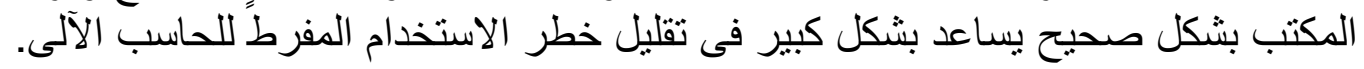

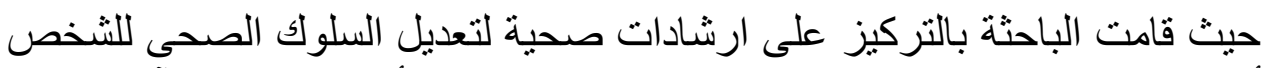

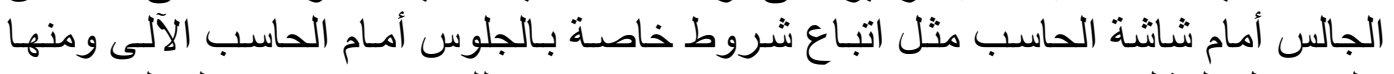

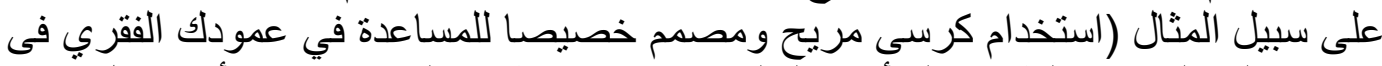

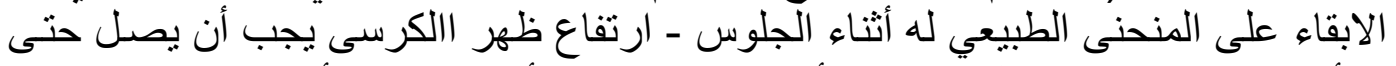

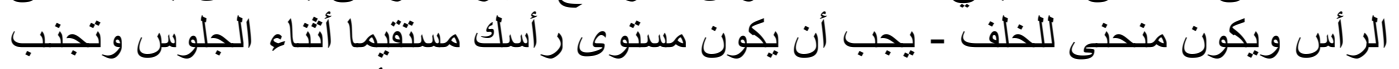

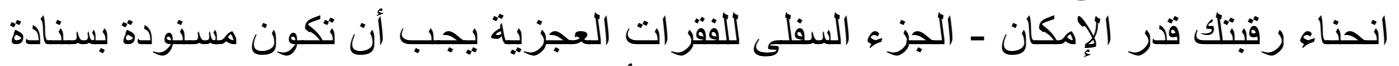

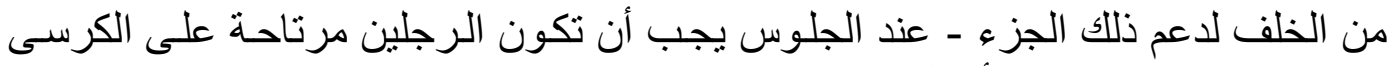

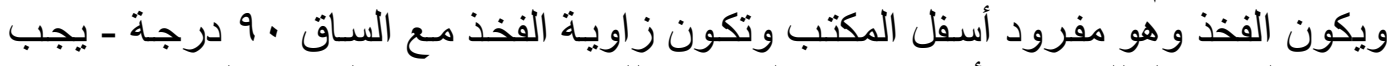

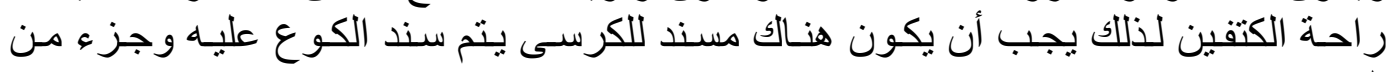

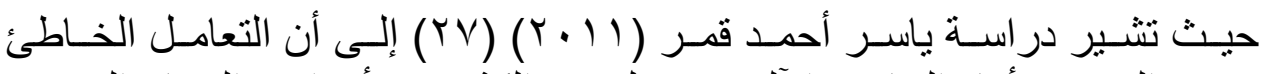

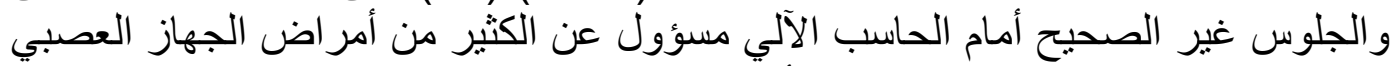

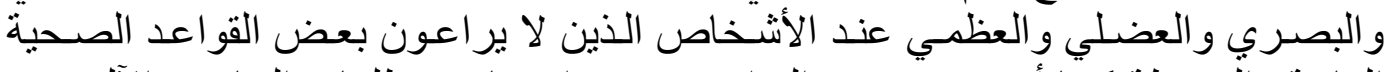

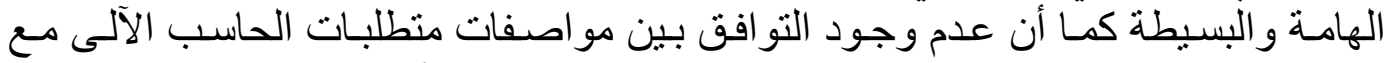

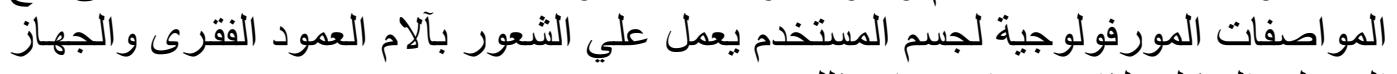

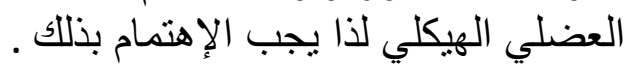

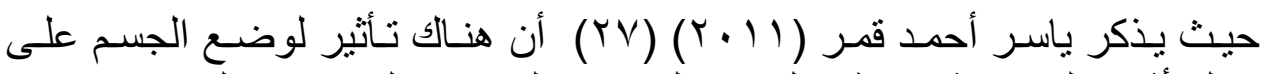

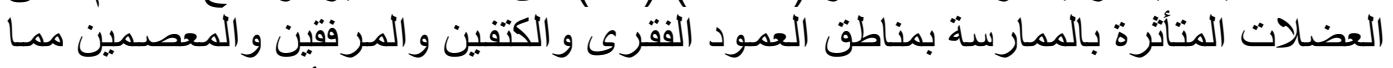

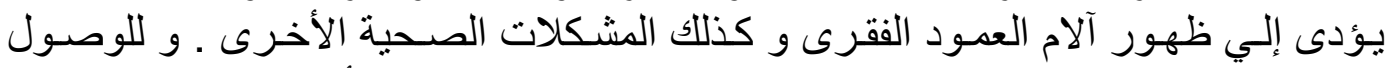

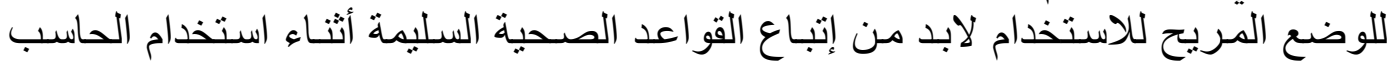


الآلي و التى تتمثل على المستوى الثخصى في خطوات الجلوس الصحيح أثناء استخدام

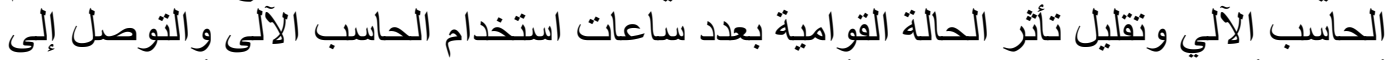

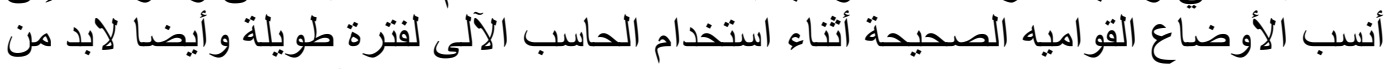

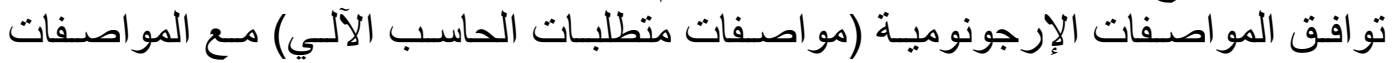

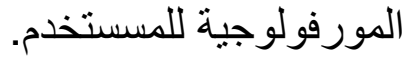

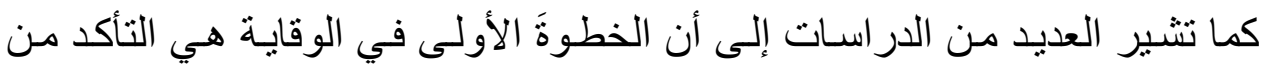

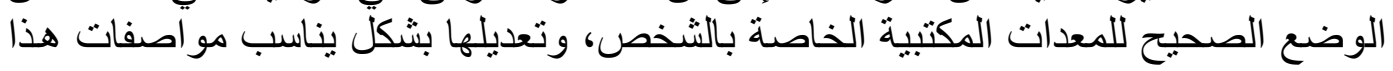

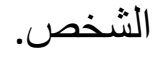

حيث أن هنـاك أدوات قابلـة للتعديل، مثل لوحسة المفاتيح القياسية و الفـأرة، بحيث

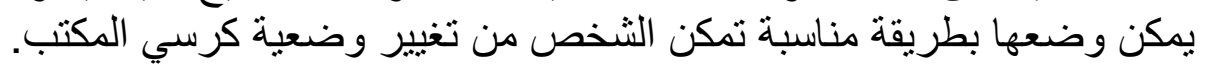

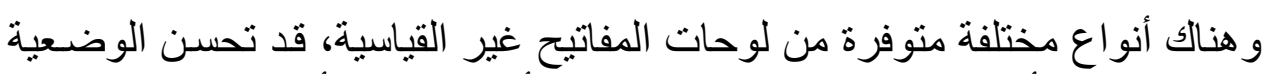

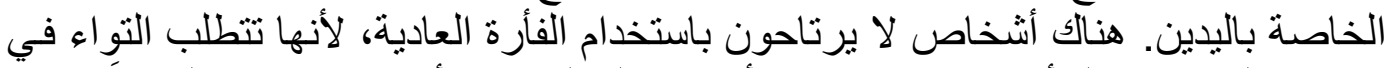

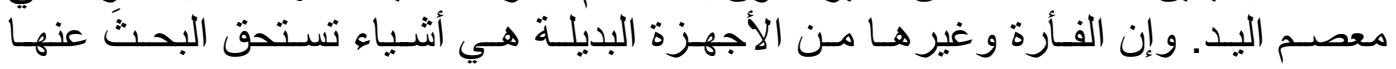

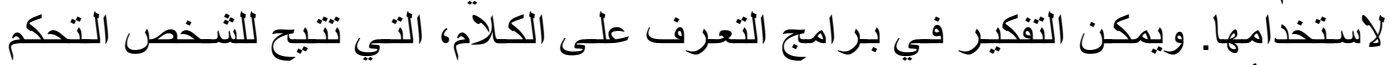
بالهاتف أو برنامج في الحاسب عن طرئ برئ استخدام صوته.

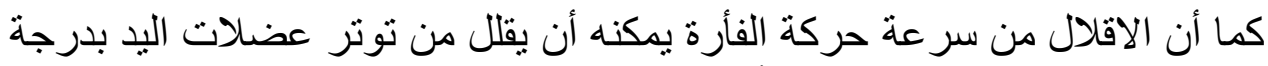

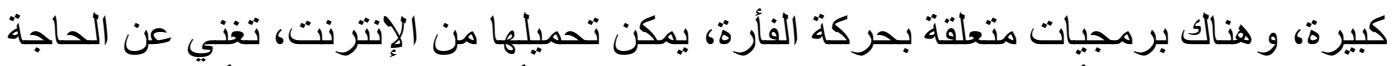

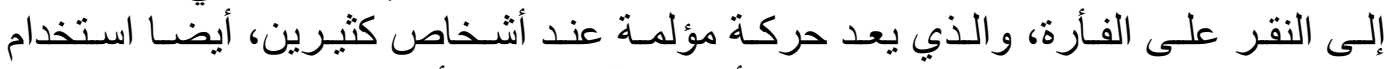

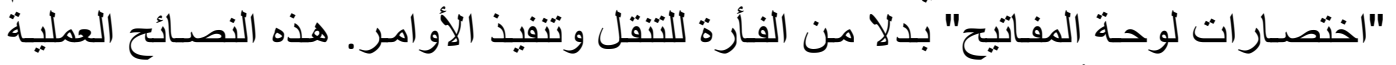

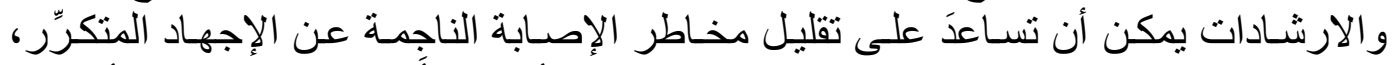

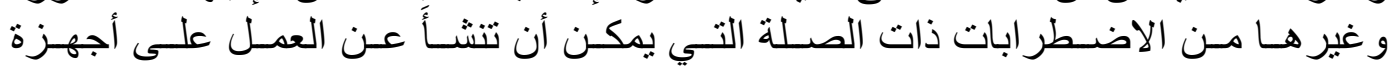

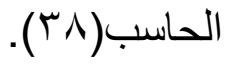

كما تشير الدراسات أيضا إلى أنه يجب عدم الجلوس لفترات طويلة فئل في الوضعية

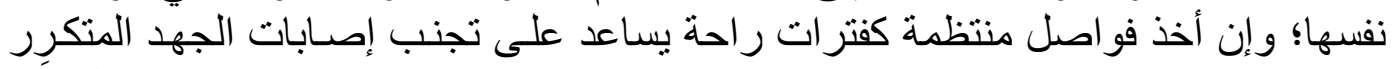

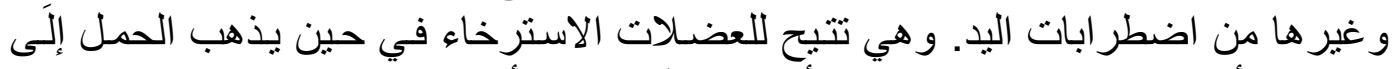

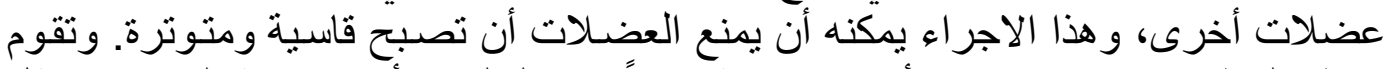

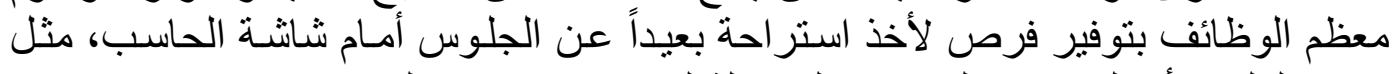

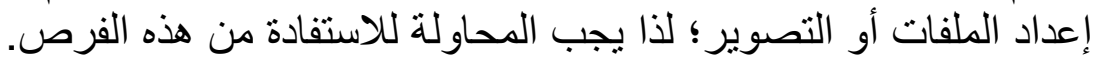

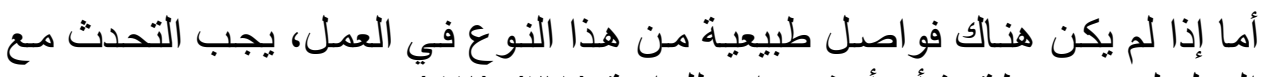

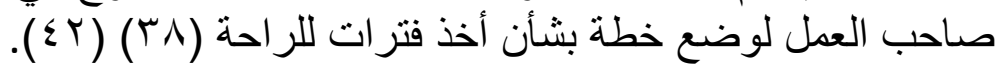

إن التدريبات تكون عامة وشاملة للطرف العلوى مما يؤدى إلى تحسن القوة العضلية

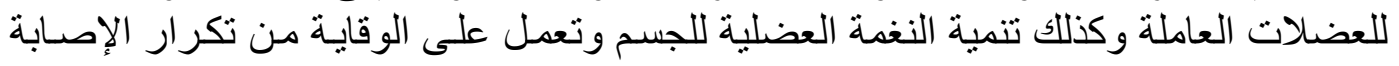


مرة أخرى، كمـا تعمل على زيادة الكتلة العضلية النشطة وتقوى الأنسجة الضـامة والجهاز

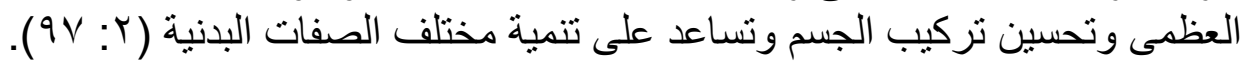

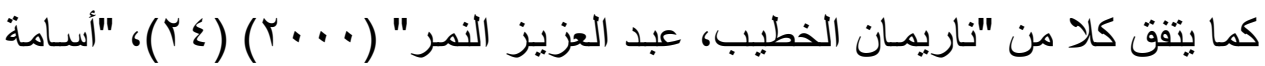

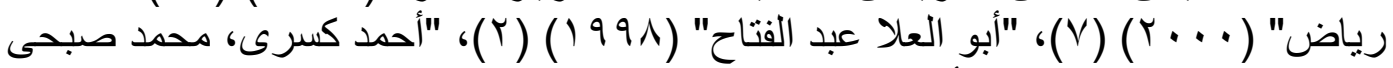

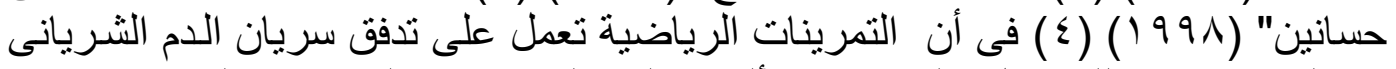

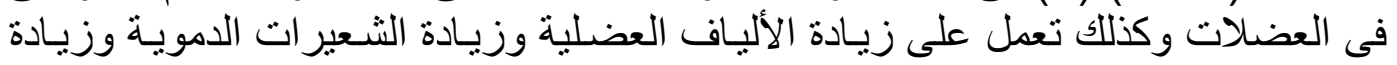

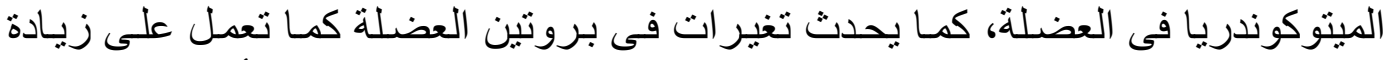

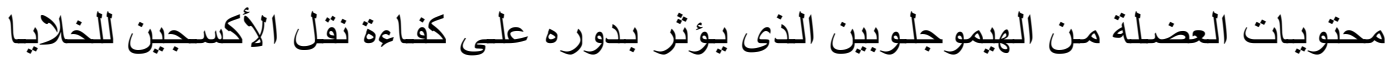

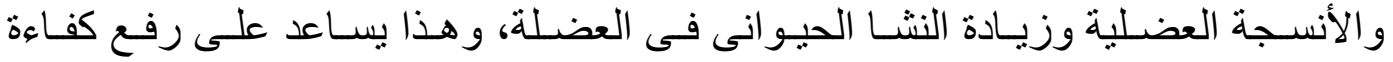

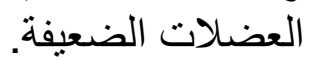

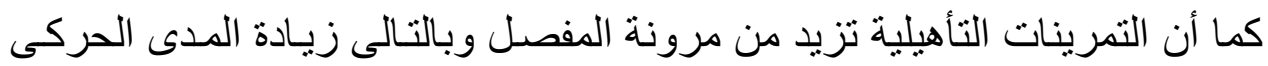

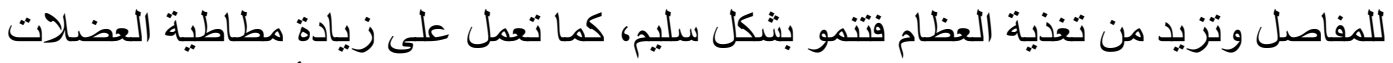

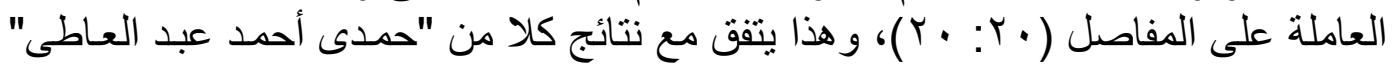

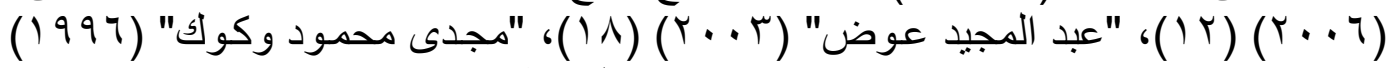

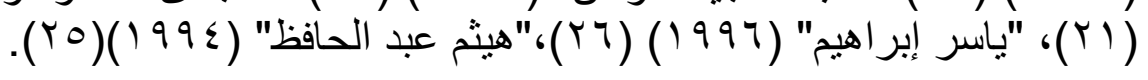

وبذلك يتحقق فرض البحث و الذى ينص على: " توجد فروق ذات دلالة إحصائيا

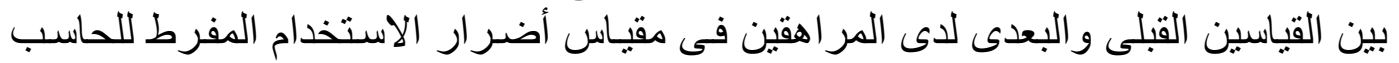

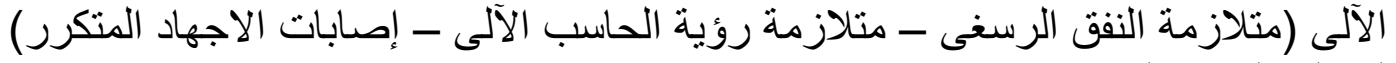

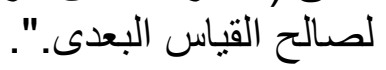

\section{الاستخلاصات والتوصيات

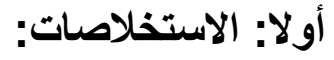

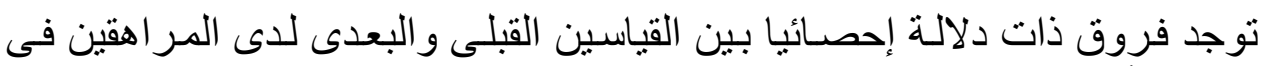

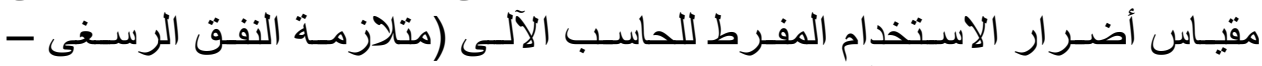

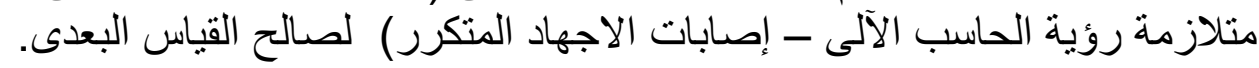

ثانيا: التوصيات

1- تعديل وضعية الحاسب الآلى بطريقة تضمن الاستخدام الصحيح طبقا لأجهزة

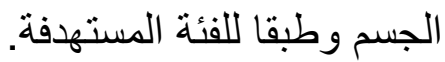

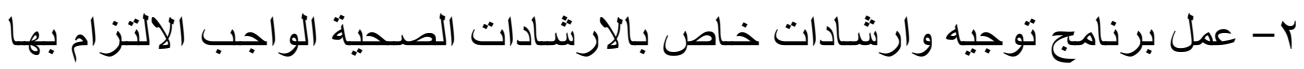

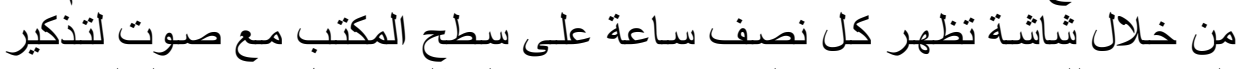

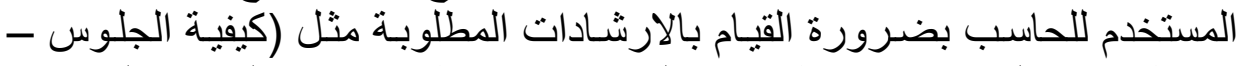

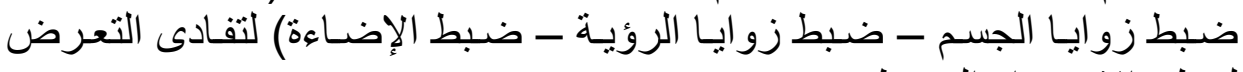

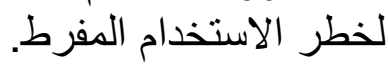

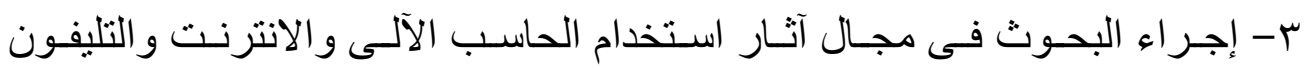

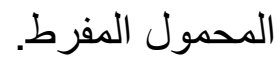


ع - زيادة الاعتماد على الثانشات التى تعمل باللمس و التى تقلل من الضغط على اليد

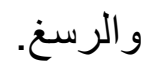

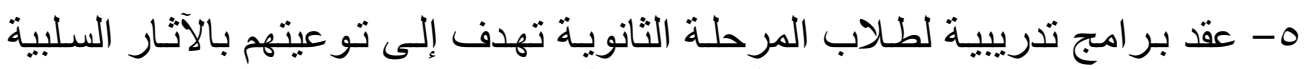

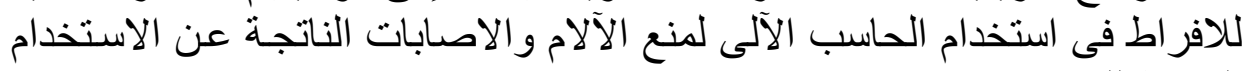

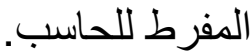

צ- عقد بر امج ارشادية لأولياء الأمور لتو عيتهم بالطرق المناسبة للتعامل مع أبنائهم

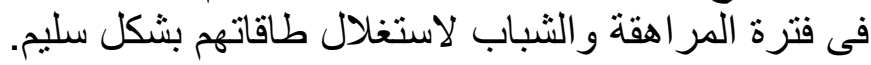

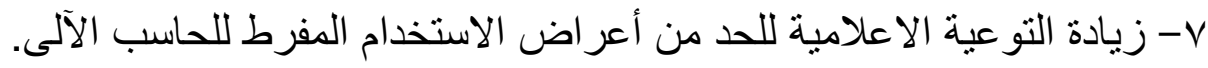

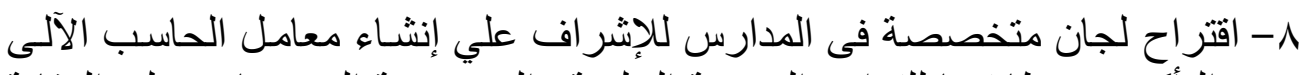

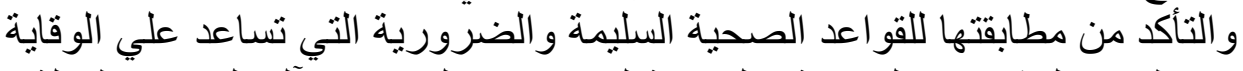
من ظهور المشكلات الصحية والقو امية لمستخدمي الحاسب الآلى لفترات طويلة الفيلة. 


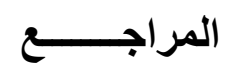

أولا: المراجع باللغة العربية :-

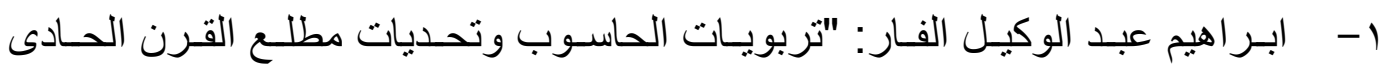

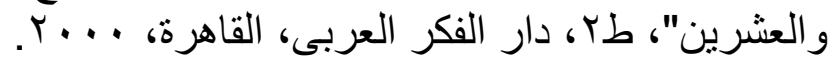

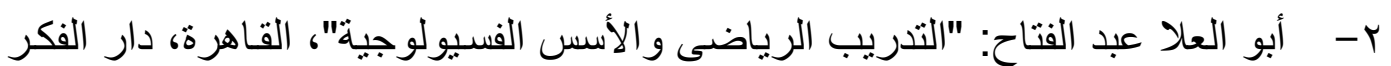

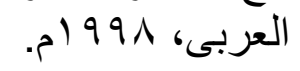

ب- أحمد صـالح ليري: "أثر المشكلات الاجتماعية والنفسية المصـاحبة لمستخدمي

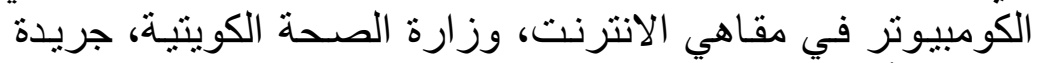

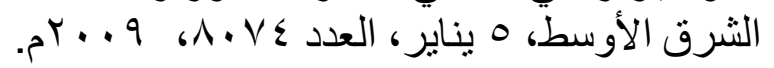

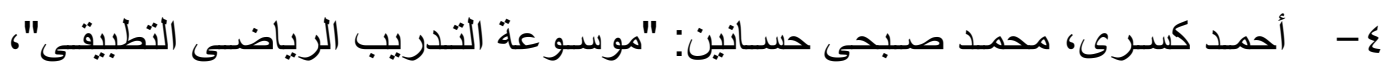

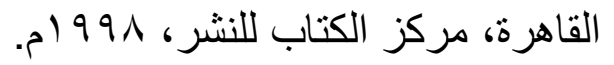

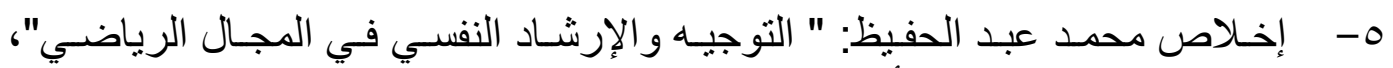

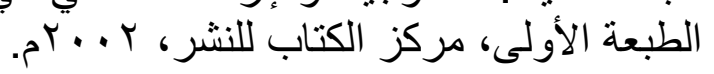

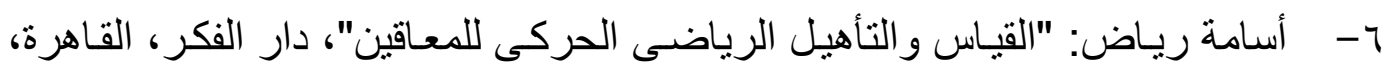

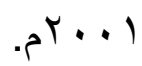

V - أسـامة ريـاض عونى: "الطب الرياضـى و العـلاج الطبيعى"، مركز الكتاب للنشـر،

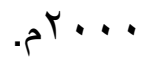

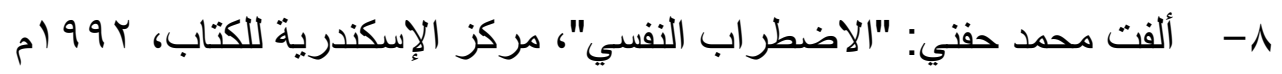

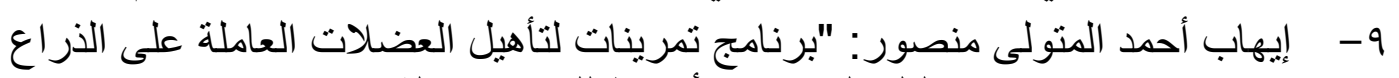

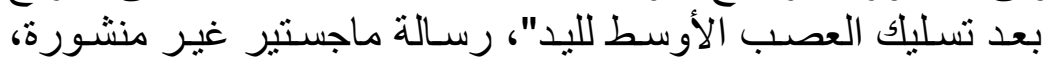

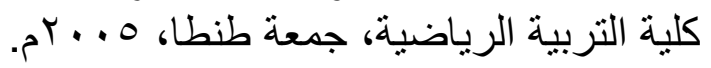
• 1- بهاء الدين إبر اهيم سلامة: " الصحة و التربية الصحية " ، دار الفكر العربي، القاهرة، (997

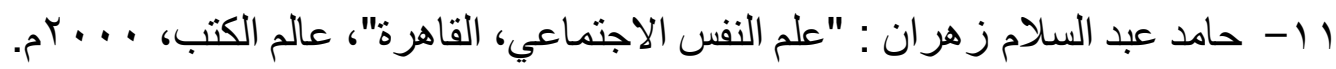

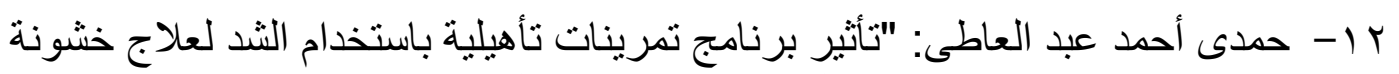

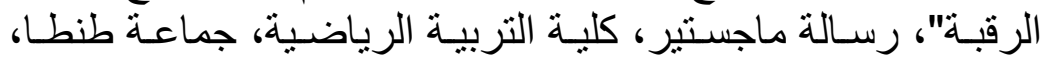

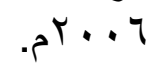

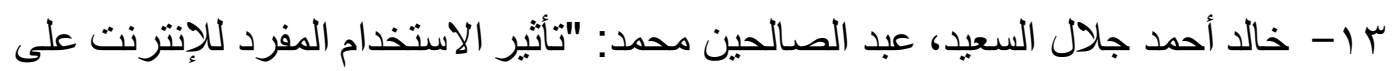

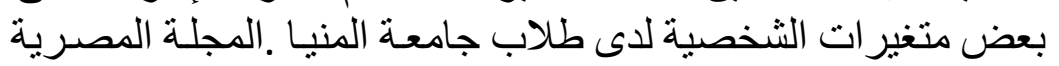

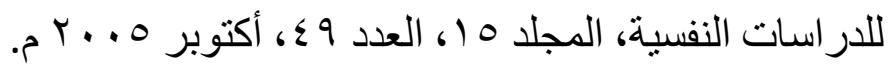

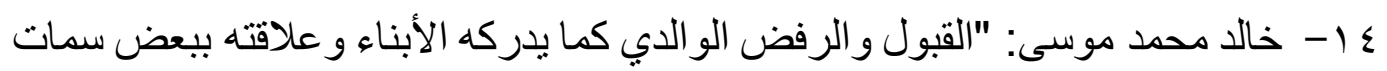

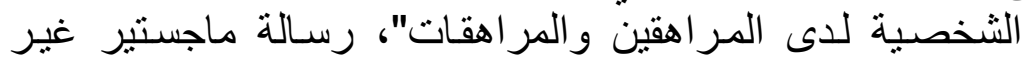

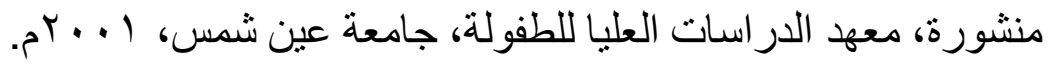




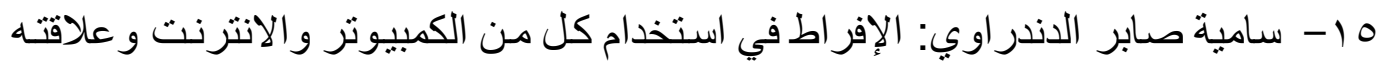

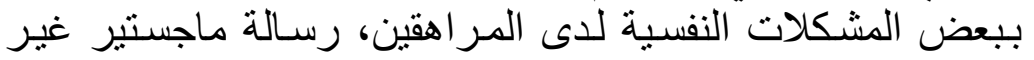

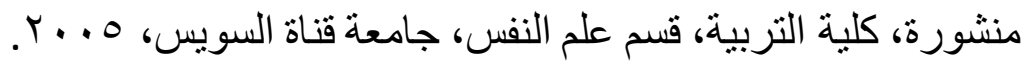

7 ا - سليمان أحمد حجر ، محمد السيد الأمين: " الأسس العامة للصحة و التربية الصحية "

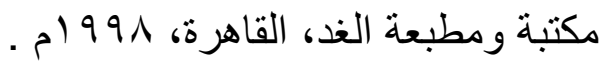

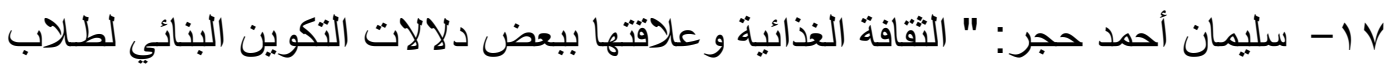

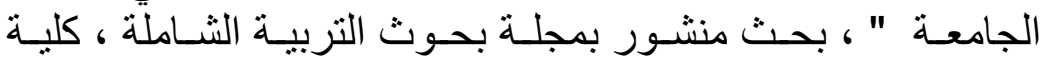

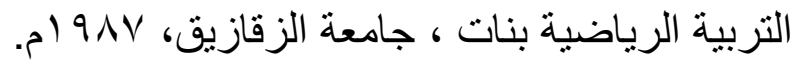

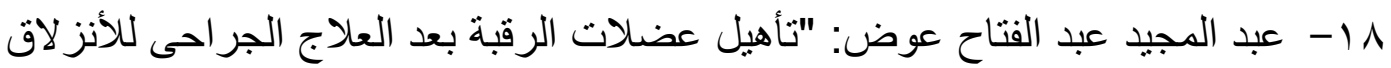

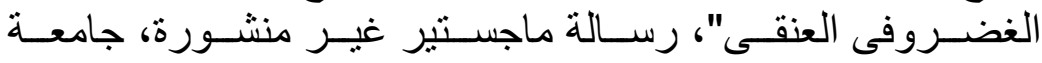

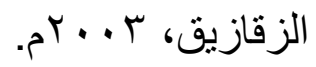

9 1 - عصام محمد أمين الخولى: "الصحة و اللياقة وضبط الوزن"، القاهرة دار المعـارف، . 91 ह

• ץ- فر اج عبد الحميد توفيق: "أهمية التمرينات البدنية فى عـلاج التشو هات القو امية، دار

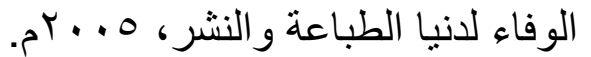

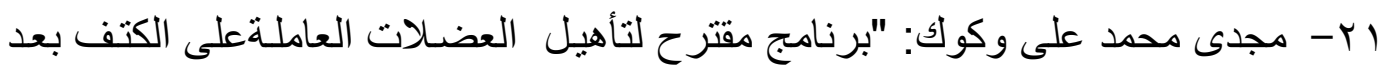

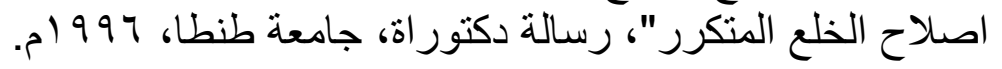

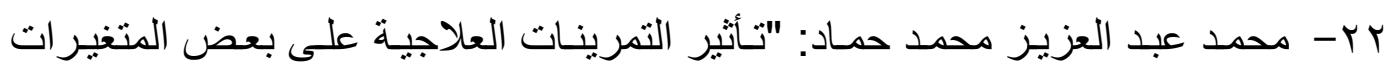

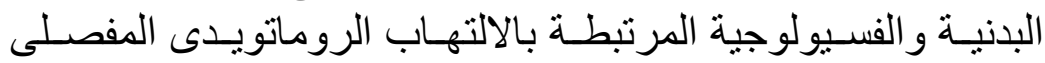

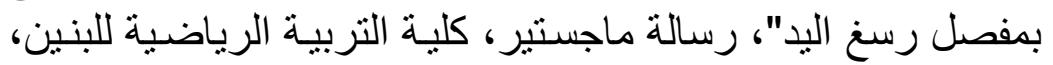

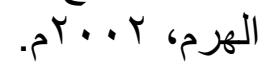

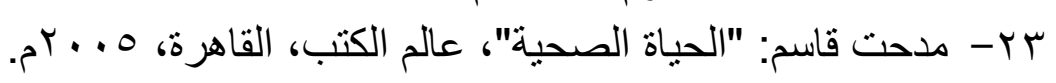

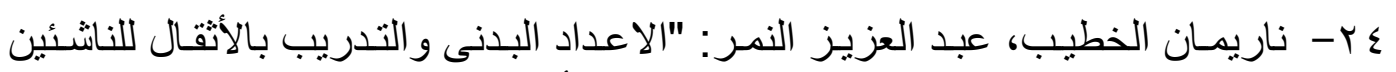

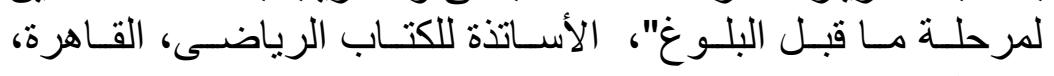

$$
\text { r... }
$$

هץ- هيثتم محمـد الحـافظ: "المقارنـة بـين أثنر الـوخز بـالإبر الصـينية والتتبيـه الكهربـائى

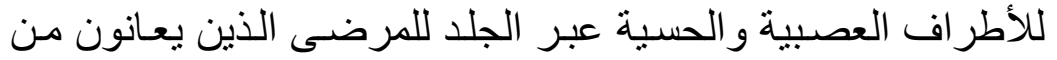

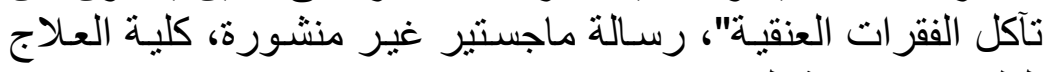

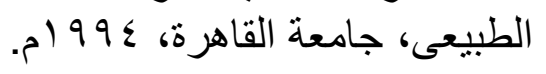

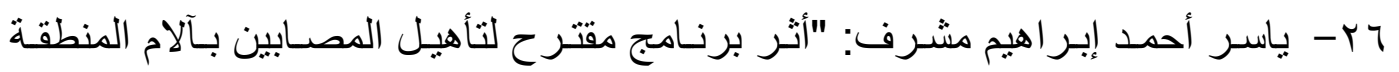

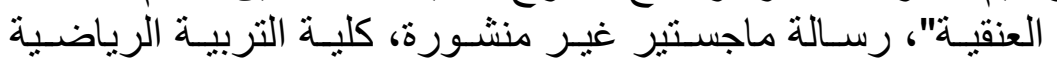

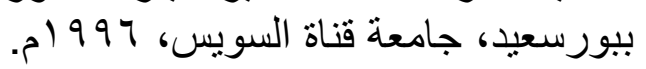

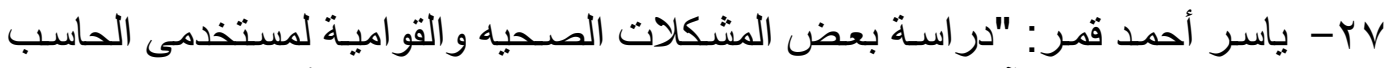

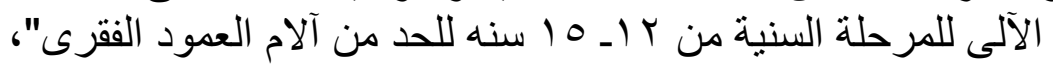

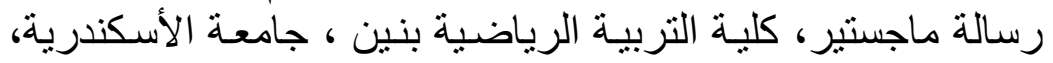

$$
\text { r. } 11
$$




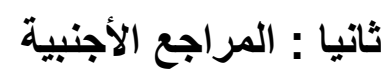

28- Ceyhan, A., \& Ceyhan, E: "Loneliness depression, and computer self-efficacy as predictors of problematic internet use", CyberPsychology \& Behavior, Volume 11, Number6, 2008.

29- Drs Andersen, Overgaard, Ms Vilstrup, Drs Thomsen, Lassen, Kryger, and Mikkelsen and Dr Brandt: "Computer Use and Carpal tunnel Syndrome". Department of Occupational Medicine, Herning Hospital, Herning, Denmark; Department of Occupational Medicine, Copenhagen University Hospital, Glostrup, Denmark; and Department of Occupational and Environmental Medicine, Odense University Hospital, Odense, Denmark, Vol. 289, No. 22, Full article.

30- kyrie27: The Bad Effects to Health of Excessive Computer Use: By | Jan. 2012, Page 1 of 6

31- Luis Ortiz-Hernández, Silvia Tamez-González, Susana Martínez-Alcántara and Ignacio Méndez-Ramírez:

" Computer use increases the risk of musculoskeletal disorders among newspaper office workers", Archives of Medical Research, July-August, 2003 Volume 34, Issue 4, Pages 331-342

32- Lu Shi1*, Yuping Mao2: "Excessive recreational computer use and food consumption behaviour among adolescents", Shi and Mao Italian Journal of Pediatrics 2010, 36:52

33- Nathan PA, Wilcox A, Emerick PS, Meadows kd, Me Cormack AL: "Effect of an aerobic exercise program on median nerve conduction and symptoms associated with carpal tunnel syndrome", Portland Hand Surgery and Rehabilitation Center, Portland, OR, USA, 2001.

34- N.Van Meeteren, J.Brakkee, F.Hamers, P.Helders, W.Gispen: "Exercise training improves condition velocity after sciatic nerve crush lesion in the rat*1", Physical Medicine and Rehabilitation, Vol78, no1,1997. 
35- Pinar L, Enhos A, Ada S, Giingor N: "Can we use nerve gliding exercises in women with carpal tunnel syndrome?", Gaz University Faculty of Medicine, Department of Physiology, Besevler-Ankara, Turkey, 2005.

\section{ثالثا: مواقع شبكة المعلومات الدولية (Internet)}

36- http://www.mayoclinic.org/diseases-conditions/carpal-tunnelsyndrome/expert-answers/carpal-tunnelexercises/faq-20058125

37- http://www.news-medical.net/health/What-is-Repetitive-straininjury.aspx

38- https://www.kaahe.org/health/ar/

39- http://www.mayoclinic.org/diseases-conditions/carpal-tunnelsyndrome/expert-answers/carpal-tunnelexercises/faq-20058125

40- http://www.allaboutvision.com/cvs/irritated.htm

41- https://saaid.net/Minute/290.htm

42- http://www.nhs.uk/

43- http://www.altibbi.com/

44- http://www.noorvision.com/ar/

45- www.painfoundation.org//--

TreatmentOptions:AGuideforPeople

LivingwithPain.AmericanPainFoundatio.2006 
المطخلص

فعالية برنامج للتوجيه والارشاد الصحى على الحد من أعراض الاستخدام المفرط للحاسب الآلى لدى الميه والارثاد الهين بمحافظة الشرقية

أ.م.د. جيهان يحيى محمود عفيفى

أستاذ مساعد بقسم العلوم الصحية مجنية

كلية التربية الرياضية بنات

جامعة الزقازيق

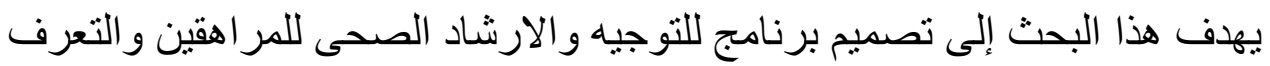

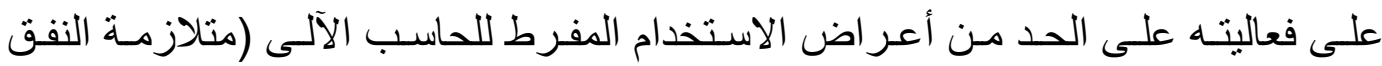

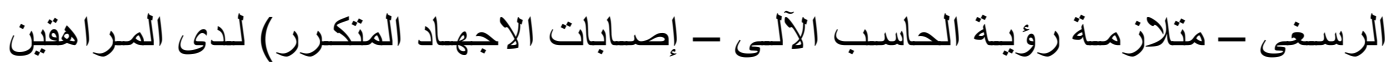

بمحافظة الثرقية.

تم استخدام المنهج التجريبى ذو القياس القبلى و البعدى لمجموعة و احدة، لتحديد

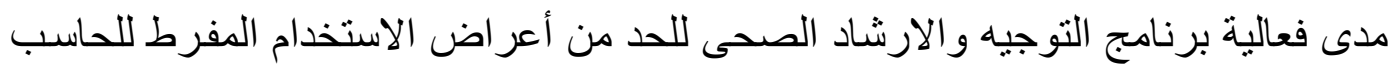

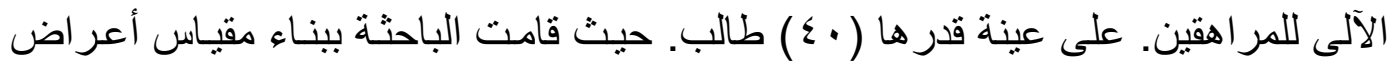

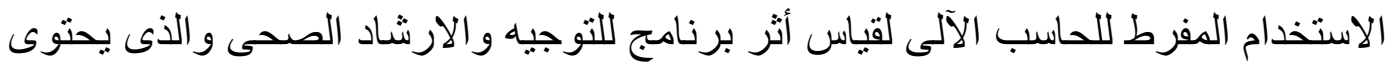

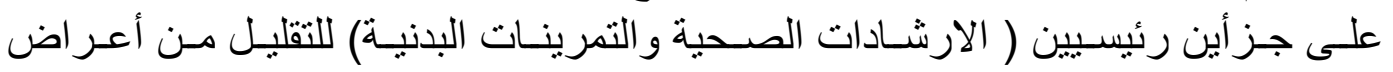

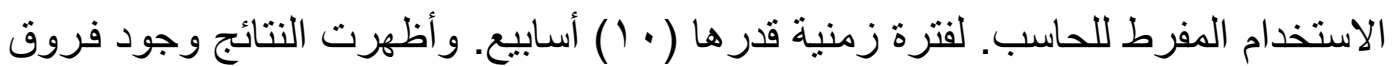

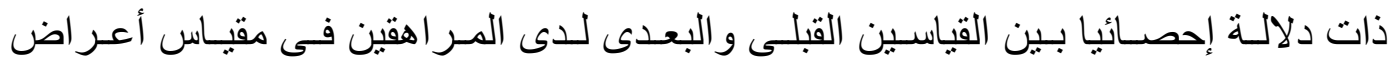

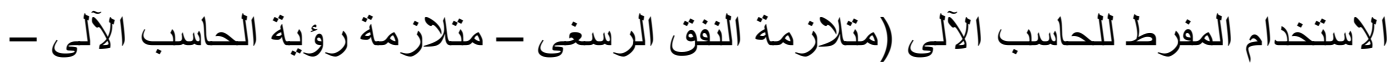

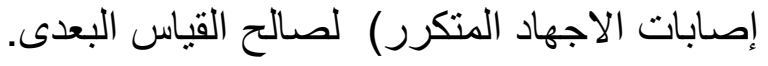

و أوصت الباحثة بضرورة تعديل وضعية الحاسب الآلى بطريقة تضـمن الاستخدام

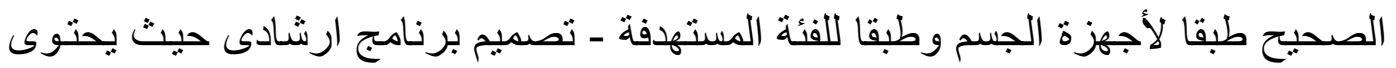

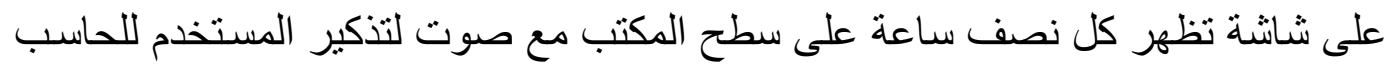

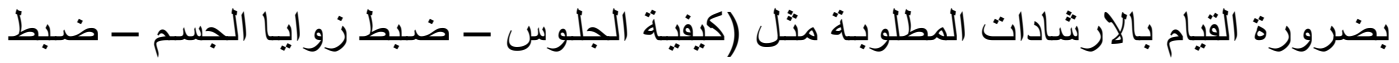
زوايا الرؤية - ضبط الإضـاءة) لتفادى التعرض لخطر الاستخدام المفرط. 


\title{
Summary
}

\section{The effectiveness of the program guide and health counseling to reduce the symptoms of excessive use of Computer in adolescents Sharkya}

\author{
D. Jihan Yahia Mahmoud Afifi \\ Assistant Prof. in Department of Health Sciences \\ Faculty of Physical Education Girls \\ Zagazig University
}

This research aims to design a program of guidance and health counseling for adolescents and identify its effectiveness at reducing the symptoms of excessive use of Computer (carpal tunnel syndrome computer vision syndrome - repetitive strain injuries) in adolescents Governorate of Sharkeya.

The researcher used the experimental method is measuring pre and post one group, to determine the effectiveness of health guidance and counseling program to reduce the symptoms of excessive use of Computer adolescents.

On a sample of 40 students. Where the researcher built a measurement of symptom of excessive use of Computer scale to measure the impact of the health program for guidance and counseling, which contains two main parts (health guidelines and physical exercise) to reduce the symptoms of excessive use of the computer.

For a period of time of (10) weeks. The results showed there is a significant statistical difference between the two measurements pre and post among adolescents in the measurements of symptoms of excessive use of Computer (carpal tunnel syndrome - computer vision syndrome - repetitive strain injury) for post-measurement.

The researcher recommended the necessity of modifying the status of the computer in a way to ensure the correct use, according to the body organs, according target group.

Design counseling program as it contains the screen every halfhour show on your desktop with the voice to remind the user of the computer need to do the required 'guidelines (such as how to sit - set the body angles - adjusting angles of vision - adjusting lighting) to avoid the risk of overuse. 